OPEN ACCESS

Edited by:

Nurin Wahidah Mohd Zulkifli,

University of Malaya, Malaysia

Reviewed by:

Jitendra Kumar Katiyar,

SRM Institute of Science and

Technology, India

Arslan Ahmed,

COMSATS University Islamabad,

Pakistan

*Correspondence:

Robiah Yunus

robiah@upm.edu.my

Specialty section:

This article was submitted to

Tribology,

a section of the journa

Frontiers in Mechanical Engineering

Received: 11 December 2021

Accepted: 27 January 2022

Published: 28 February 2022

Citation:

Raof NA, Hamid HA, Mohamad Aziz NA and Yunus R (2022)

Prospects of Plant-Based

Trimethylo/propane Esters in the Biolubricant Formulation for Various

Applications: A Review.

Front. Mech. Eng 8:833438.

doi: 10.3389/fmech.2022.833438

\section{Prospects of Plant-Based} Trimethylolpropane Esters in the Biolubricant Formulation for Various Applications: A Review

\author{
Nurliyana A. Raof ${ }^{1}$, Hamidah Abd Hamid ${ }^{1}$, Nur Atiqah Mohamad Aziz $^{2}$ and Robiah Yunus ${ }^{2 \star}$ \\ ${ }^{1}$ Institute of Plantation Studies, Universiti Putra Malaysia, Selangor, Malaysia, ${ }^{2}$ Department of Chemical and Environmental \\ Engineering, Faculty of Engineering, Universiti Putra Malaysia, Selangor, Malaysia
}

Biodegradable lubricants from renewable feedstocks have been successfully developed to meet the demands of new machines with stringent requirements of the global standards, which address sustainability and environmental policy. Trimethylolpropane ester (TMPE) has been extensively evaluated as a biolubricant base stock and occasionally used as an additive, due to their low toxicity and excellent biodegradability. The formulation of highperformance TMPE-based lubricants involves addition of surface additives, multifunctional additives, and solid nano particles. This review focuses on the development of plant-based TMPE formulation for various applications, namely food-grade lubricant, engine oil, drilling fluid, insulating fluid, metal working fluid, hydraulic and heat transfer fluids. Even though plant-based TMPE lubricants have huge advantages over mineral oils, they have other challenging issues such as limited load-bearing capacity, hygroscopic properties, and high risk of toxic emission owing to additives selection. The details on the performance characteristics of TMPE as base stocks and additives are discussed, including the current prospects and challenges in the respective areas. This review concludes with a brief discussion on suggestions and recommendations for future advancement in the usage of TMPE and the remaining issues that must be overcome to allow for its full potential to be realized.

Keywords: biolubricants, trimethylolpropane ester, environmentally friendly lubrication, formulation, additives

\section{INTRODUCTION}

Formulations of lubricants by using a conventional mineral oil and additives have raised crucial drawbacks, such as global scarcities due to a rapid exploitation of fossil oil resources, high toxicity, and non-biodegradability. The usage of mineral oil-based lubricants as the end products could adversely affect the environment due to an accidental loss, spillage, or a poor lubricant handling or management. In this case, due to its renewable, low eco-toxicity, biodegradable, and safer attributes, biolubricants derived from plant oil have become a great interest. While plant-based oils have long been used as lubricants, they were rapidly overshadowed in the 20th century by mineral oils, which are significantly cheaper. However, with the present increase in plant-based chemistry and skyrocketing petroleum crude oil prices, biolubricants are regaining popularity. The performance of biolubricants, however, particularly in terms of friction, wear prevention, and lubricity, remains debatable. One of the main attributes for an excellent lubrication is high affinity toward metal 
surfaces. A plant-based oil with a long chain fatty acid is normally required to increase lubrication and protection against friction and wear (Arumugam et al., 2014; Kotturu et al., 2020; Tulashie and Kotoka, 2020). The majority of research to date has looked at the friction and wear properties of vegetable oils alone or in the addition of particular additives. (Nair et al., 2017) has reported on the thermal and tribological performance of sesame oil as a lubricant base stock. While sesame oil is shown to have exceptional thermal and tribological characteristics, its viscosity range and oxidative stability should be enhanced. An extensive review on the use of palm oil and its challenges as a lubricant base stock has been reported by Dandan et al. (2018). The experimental findings showed that the palm oil suffers poorer thermal and oxidative stability and is also less effective under extreme loads (Dandan et al., 2018). Recently, Salaji and Jayadas (2021) have reported on the potential of nonedible chaulmoogra oil as the lubricant base stock. Although the lubricant displays a lower coefficient of friction, the wear scar diameter was significantly larger. The reported pour point of only $15^{\circ} \mathrm{C}$ needs to be further improved too.

In summary, the use of plant oils as lubricating oil is always associated with certain limitations such as poorer lowtemperature properties and poor oxidative stability during usage (Owuna, 2020; Yunus et al., 2004; Yunus et al., 2005). The alteration of plant oils' molecular structures or a blending with commercial oil, chemical additives, or nano-particles would further envisage the physicochemical properties of biolubricants, especially along boundary and hydrodynamic lubrication regimes (Chan et al., 2018; Hamdan et al., 2018; Gul et al., 2020; Kotturu et al., 2020; Srinivas et al., 2020). The chemical modifications of plant oil such as by epoxidation (Afifah et al., 2021; Bashiri et al., 2021), transesterification (Robiah et al., 2003; Aziz et al., 2014; Hamid et al., 2016; Zulkifli et al., 2016; Raof et al., 2019a), esterification (Fernandes et al., 2018; Kim et al., 2019; Rochmat et al., 2020), hydrogenation (Troncoso and Tonetto, 2022), and estolide formation (Salimon et al., 2011; Hoong et al., 2019) have been carried out to overcome the limitations by plant oils. In esterification/transesterification reactions, the acids or alcohols used have a direct impact on the physicochemical properties of the produced esters, known as synthetic esters. Synthetic esters, generally, have better properties than their corresponding plant oils. Synthetic esters exhibit better lowtemperature properties, higher flash and fire points, lower volatility, and higher oxidative stability (Cecilia et al., 2020). Compared with plant oils that is also a natural ester, the substitution of the glyceride moiety with a polyhydric alcohol such as neopentylglycol (NPG), trimethylolpropane (TMP), pentaerythritol (PE), or dipentaerythritol (diPE) can substantially increase plant oil's thermal and hydrolytic stabilities. The reaction of either monobasic acid or monoesters (usually methyl) with any polyhydric alcohol in the presence of a catalyst will produce polyol ester and is commercially available in the market in the wide range of viscosities and other physical properties (Randles, 2013). Among these polyol esters, trimethylolpropane ester (TMPE) has been more widely used in many applications since it has been more available and less costly.
The main role of lubricants is to reduce friction and to prevent wear and seizure. The other two major functions of lubricants are to provide a cooling effect between two-contact surfaces and to circulate between surfaces as a cleaning aid from external dusts, deposits, or wear particles. An excellent lubricant performance is obtained by the blending of lubricant base oil with selected additives (Rao et al., 2018). Lubricant additives could be categorized into several large groups based on their working functions (see Figure 1), which are tribology-improving additives, rheology-improving additives, condition-maintaining additives, and auxiliaries (Minami, 2017). The tribologyimproving additives that directly improve the tribological performance of lubricants are friction modifiers, anti-wear agents, and extreme-pressure additives. Meanwhile, an enhancement of a base oil fluidity in a hydrodynamic regime is usually by using rheology-improving additives such as nano particles of viscosity modifiers and pour point depressant. For a prolonged lifetime of lubrication system and in certain cases, an improved lubrication performance, condition-maintaining additives were added. The additives of this group are such as antioxidants, detergents, dispersants, corrosion inhibitor, antifoam agents, and demulsifiers. In addition, the last group of additives for a specific purpose other than working functions that are mentioned earlier are categorized as auxiliaries. Excellent lubricant performance can often be obtained using suitable additive technology (Rao et al., 2018). For the development of sustainable lubricants, biodegradability and toxicity are two most important criteria to be considered. While the first concern is usually addressed by utilizing a biodegradable base fluid, low toxicity requires the use of environmentally friendly additives. It should be emphasized that several additive classes are toxic and may bioaccumulate in the environment.

Table 1 highlights some of the review articles that have been published in the last 5 years that discuss the potential of plantbased oils as an alternative in the production of lubricants for numerous industrial applications. Various biolubricant feedstocks have been discussed including specifically from vegetable oils (Masripan et al., 2020; Owuna, 2020; Wang X et al., 2020; Rasep et al., 2021) and nonedible oils (Singh et al., 2017; Singh et al., 2019; Almasi et al., 2021). Recently, Owuna et al. (2020) presented a short review on the use of TMPE as biolubricants. A detail and comprehensive review on the specific application of TMPE can be a new and valuable addition to the current literature. Therefore, in this article, the application of TMPE as a synthetic lubricant base oil or as a major component in biolubricant formulations is thoroughly reviewed.

\section{BIOLUBRICANT MARKET AND DEMANDS IN THE POST-COVID-19 ERA}

Biolubricants are typically employed in niche markets, where recovery is difficult or where they are likely to be discharged into the environment. First, biolubricants are used in the lubrication of oven chain, chainsaw chains, bars, etc. During the use of the tools, oil is subjected to high temperature and virtually all of the lubricant ends up in the environment. Engine lubrication is 


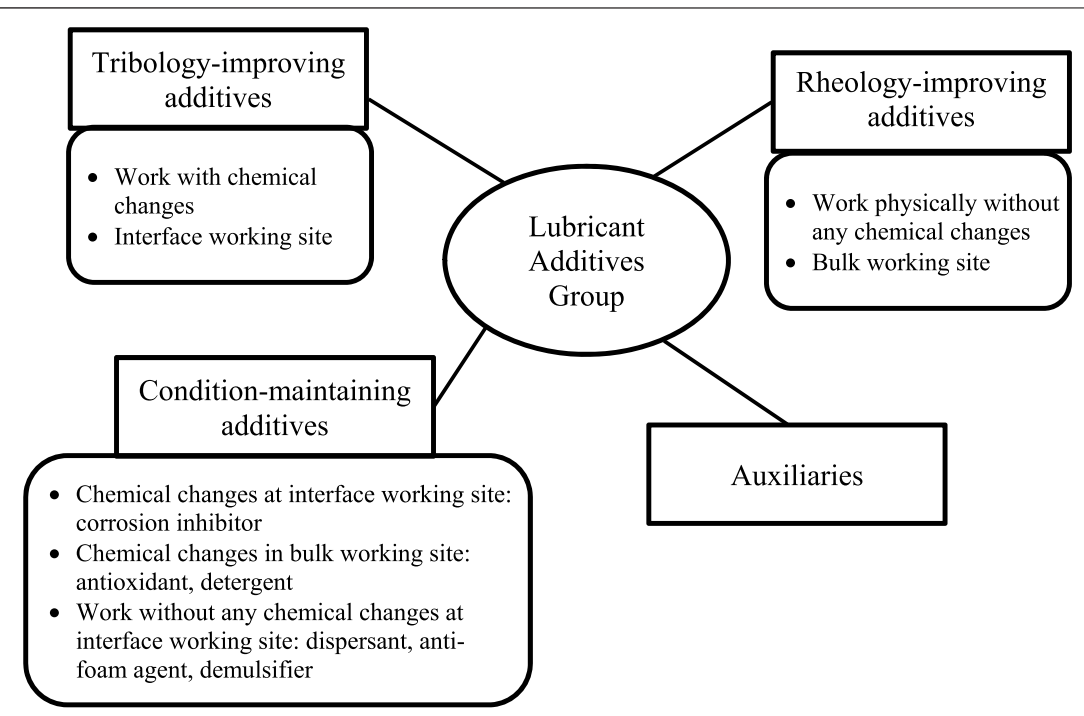

FIGURE 1 | Working function groups of lubricant additives (Minami, 2017).

TABLE 1 | Summary of a previous review paper that highlighted the potential of vegetable oil as bio lubricant in general/specific application.

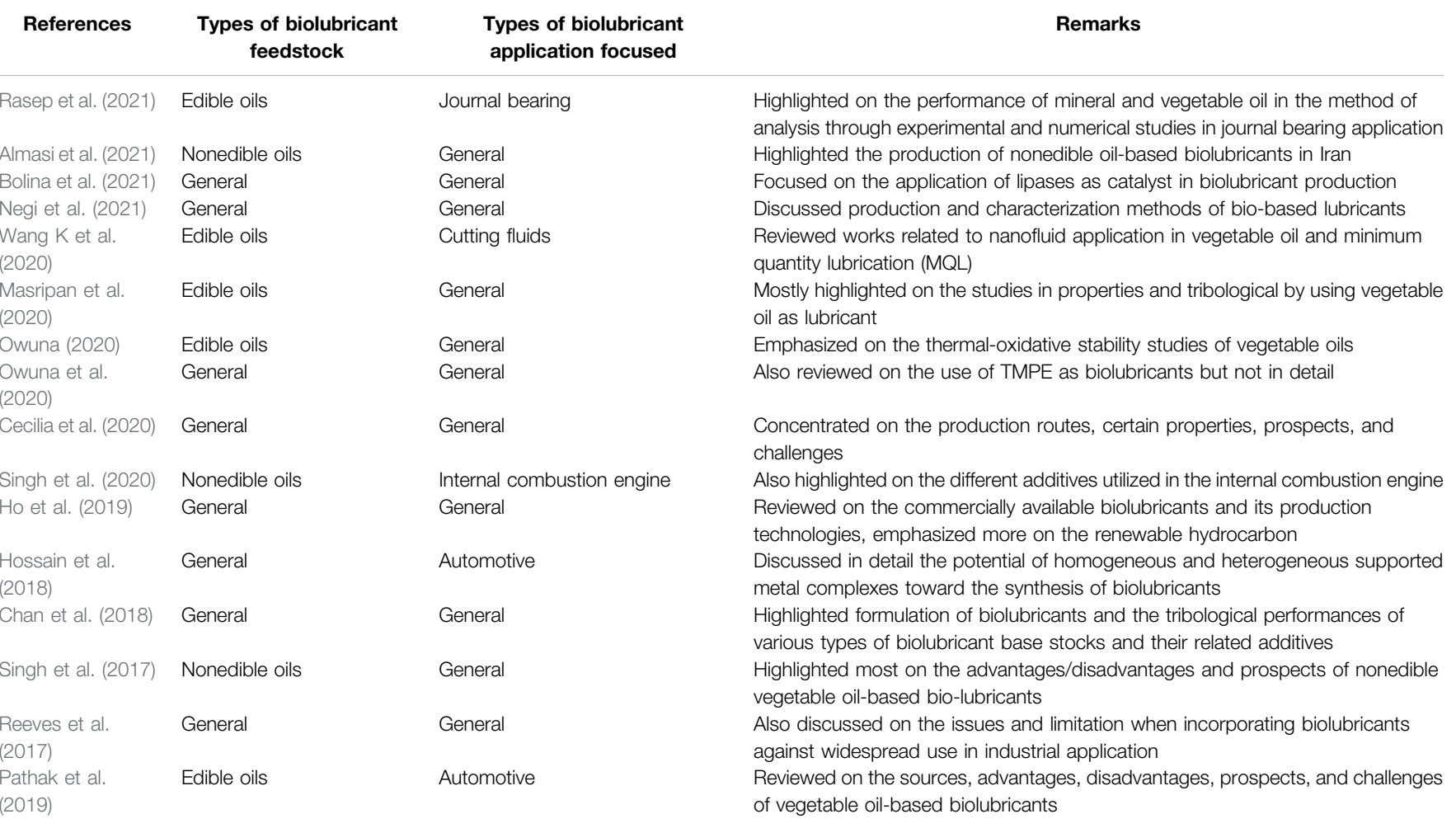

another application for biolubricants. Indeed, plant-based oilbased motor lubricants have been created to better withstand severe thermal stresses. Plant-based lubricants are also utilized as hydraulic fluids to improve the performance of forest equipment such as harvesters, cranes, tractors, and load carriers. Some machines and electrical components also require insulating lubricants or also known as insulating fluids, to avoid electrical discharges between surfaces at various electrical potentials, which can be found within transformers, for example. Because of their specific heat and thermal conductivity characteristics, lubricants can assist in the removal of heat generated by these systems. Finally, the 
application of biolubricants can also be found in the area of machining and metal working (cutting oils, cooling parts, corrosion protection, etc.), marine oils, drilling fluids, gear oils, etc. (Aranzabe et al., 2011).

The growing prospects for sustainable solutions, such as green buildings and sustainable lubricants, are expected to drive worldwide biolubricant demand, particularly in the postCOVID-19 era. According to the recent report by Global Industry Analyst Inc., the global market for biolubricants is expected to reach united States $\$ 2.6$ billion with a post COVID-19 CAGR of 5.2\%, over the analysis period of 2020-2027 (Global Industry Analysts, 2021). Biolubricants remain popular, notably in Europe, where demand is fueled by subsidies, tax incentives, and national and international labeling systems (Global Industry Analysts, 2021). According to the industry analyst, biolubricants in Asia are unlikely to take off unless governments give incentives or regulations for their usage. Malaysia looks to be taking moves in this direction as more grants have been disbursed by the government to upgrade and establish more biolubricant plants for automotive and industrial uses (LubesNGreases.com, 2021).

The global consumption of TMPE is expected to see a significant growth in the coming years owing to the fastgrowing markets for end-user industries of polyol esters (Persistance Market Research, 2017). The market for food grade lubricant is expected to increase at a compound annual growth rate (CAGR) of $7 \%$ from the united States $\$ 182.8$ million in 2016 to united States $\$ 256.5$ million by 2021 . Globally, the market is anticipated to reach 64.5 kilotons by 2021, with a CAGR of $6.7 \%$ from 2016 (Salih and Salimon, 2021). The selection and preparation of raw materials, intermediates, and finished products for food grade lubricants is more stringent and acute. One of the issues that engineers have is determining the qualification of food grade lubricant, which is determined by the chemicals and processing methods used. The lubricant should not change food performance and achieved high-speed machinery standards in food processing and packaging.

For transformer insulating oil, the global market is expected to grow at a CAGR of $6.5 \%$ from an anticipated market value of USD 1.9 billion in 2021 to USD 3.3 billion by 2030. The expansion in the industrial and commercial factors has resulted in the increase in demand for electricity and power generation capacity (MarketsandMarkets, 2021). Among that, ester-based transformer oil market is expected to reach USD 94 million by the end of 2027, growing at a CAGR of 1.8\% during 2021-2027. The next few years will witness the increasing popularity of biobased and naphthenic transformer oil in the market, mainly due to the increase in fire accidents in mineral oil-based transformers and the nonbiodegradable nature of mineral oil. The innovation involving fire-resistant transformer oils is expected to open new growth opportunities for the ester market over the foreseeable period (MarketsandMarkets, 2021).

Despite the negative impact on the biolubricant market during COVID-19 pandemic, a global metalworking market is forecasted to reach USD 11.6 billion by 2027 , with a CAGR of $4.3 \%$ during a projected period of 2020-2027 (Fortune Business Insights, 2020). The biolubricant market is moving toward bio-based metalworking fluid from synthetic esters and plant oils although it currently still holds a low share as compared with the mineral oil-based metalworking fluid. This forecasted market is due to stringent regulations of related agencies, such as Environmental Protection Agency (EPA), Occupational Safety and Health Administration (OSHA), The National Institute of Occupational Safety and Health (NIOSH), and Canadian Centre of Occupational Safety and Health (OSH). In addition, increasing demands mainly in automotive sectors and transportation during post COVID-19 pandemic become the driving factors to the expected market growth. The other potential applications in the future market of bio-based metal-working fluids include machining in construction or agriculture, electrical and power, telecommunication, and healthcare.

On the other hand, a moderate projection of the global drilling fluid market size has been forecasted to achieve USD 11.1 billion from 2020 to 2027, with a CAGR of 4.2\% (Grand View Research, 2020). Nowadays, biolubricant drilling additives are increasingly being used to develop bio-based drilling fluids, which becomes the main driving factor to a drilling fluid additives market. According to Data Bridge Market Research, it is expected that the market is growing at a rate of $9.2 \%$ from 2021 to 2028 . The potential commercial bio-based drilling additives include surface modifiers, dispersants, corrosion inhibitors, fluid viscosifiers, biocides, and defoamers (Data Bridge Market Research, 2021). An intensifying activity of oil exploration and production in Asia Pacific countries such as China, Australia, Brunei, and Indonesia leads to a highest forecast growth rate over a period from 2020 to 2027. Meanwhile, a significant growth rate over the forecast period of synthetic-based fluids is due to its low toxicity, low bioaccumulation potential, and lower fluid loss when compared with other drilling fluid products such as water-based fluids and oil-based fluids (Grand View Research, 2020).

\section{CHARACTERISTICS OF TRIMETHYLOLPROPANE ESTER FOR DEVELOPMENT AND SELECTION}

TMPE is a hydrolytically stable and biodegradable polyol ester. TMPE contains three branches of ester functional groups that are attached to a TMP polyol molecule. TMP polyol is an organic alcohol that contains 3 hydroxyl functional groups and appears as clear to white solid phase in an ambient condition. TMPE can be synthesized mainly via esterification of fatty acids or transesterification of methyl esters with TMP alcohol. For optimum application performance, fatty acids or methyl esters of appropriate chain lengths and degree of unsaturation are utilized in the synthesis methods. The increase in branch length in the TMP structure increases the molecular weight and improves the lubricity properties at low temperature (Mahmud et al., 2015; Samidin et al., 2021). A significant branching group near the midpoint of a fatty acid chain from TMP's backbone causes a steric hindrance, which slows the crystallization process. As a result, the pour point and cloud point of the TMPE would be significantly improved. For example, Samidin et al. (2021) modified the chemical structure of TMPE to 


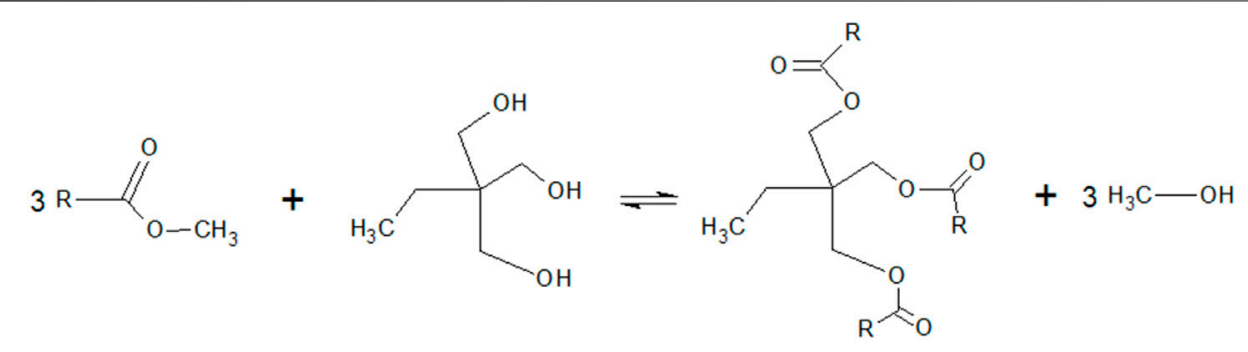

methyl ester

trimethylolpropane

trimethylolpropane ester

methanol

FIGURE 2 | Transesterification of plant oil-based methyl ester with trimethylolpropane (Raof et al., 2019a).

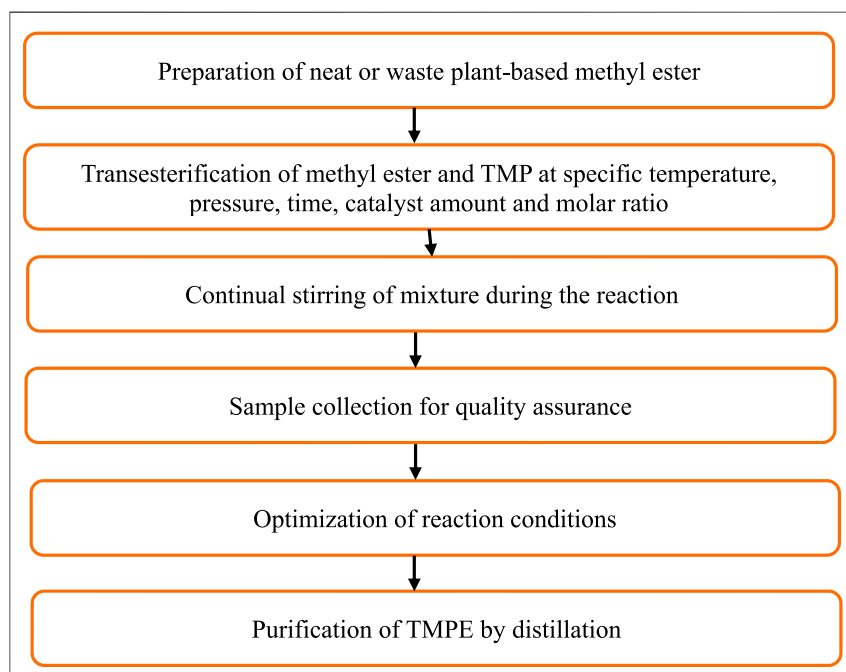

FIGURE 3 | TMPE production via transesterification reaction flow chart (Zulkifli et al., 2013).

hyper-branched nonaoleate TMP (NOTMP) through epoxidation, ring-opening reaction and further esterification reaction for improved thermal stability. NOTMP has a viscosity index of 237, which is quite high. The inclusion of polar groups in the ester increased its polarity, which was claimed to reduce wear and confirm its ability to be utilized without additives. According to Salih et al. (2013), the polar end groups will increase the adsorption of TMPE onto the metal surfaces and reduce the surface energy, which will further enhance the lubricity.

The most important lubricating function for an adequate protective film thickness is highly dependent on fluid viscosity, making it the most important characteristic for lubricant selection and application (Rashmi et al., 2017; Zulkifli et al., 2013). The viscosity should be high enough to provide a thick film between moving components even at high temperature and pressure, yet low enough to keep the lubricant fluid around each component part (Sharma and Sachan, 2019). For an example, palm oil that is known as a biodegradable resource has a viscosity and viscosity index of $40.0 \mathrm{~mm}^{2} / \mathrm{s}$ (at $40^{\circ} \mathrm{C}$ ) and 191, respectively (Kotturu et al., 2020). A transesterification of

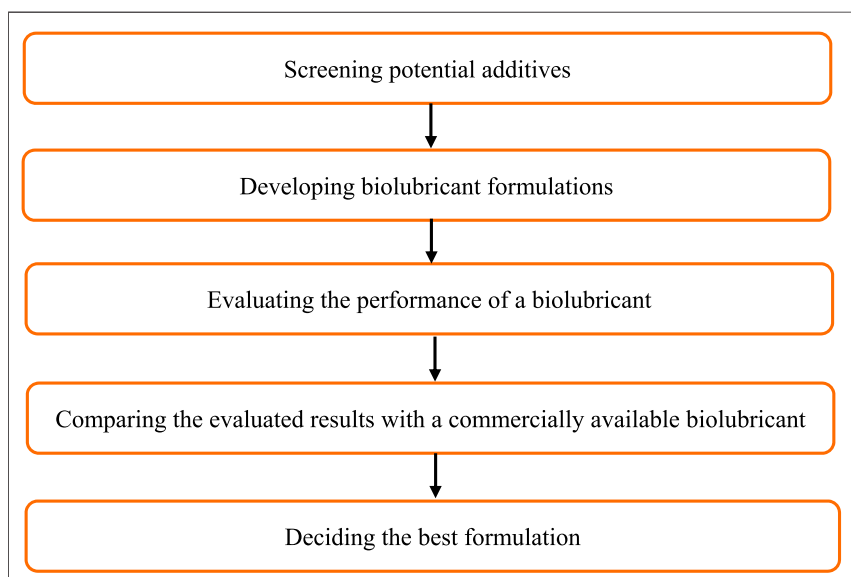

FIGURE 4 | TMPE as a base oil or an additive in a biolubricant formulation flow chart (Aziz et al., 2016).

methyl ester that is derived from palm oil with TMP to produce TMPE (Figure 2) has shown better lubricity properties, with a viscosity of $42.5 \mathrm{~mm}^{2} / \mathrm{s}\left(\right.$ at $40^{\circ} \mathrm{C}$ ) and a viscosity index of 221 (Kotturu et al., 2020; Qiao et al., 2017). In a different study, Kamarudin et al. (2020) produced TMPEs from nonedible oils such as waste cooking oil and rubber seed oil via two-stage transesterifications and found that the viscosities of both TMPEs satisfied ISO VG46 lubricant standard. The modification of the structure of vegetable oil to remove the $\beta$ hydrogen that is susceptible to oxidation improved the lubricity of a biolubricant in terms of oxidative and thermal resistance (Aziz and Atiqah, 2015). Furthermore, an esterification of Moringa oleifera oil with TMP has interestingly shown a high viscosity index of 170 and high thermal stability (Moreira et al., 2020). The synthesis studies of TMPE from other plant oils such as palm kernel oil, crude Jatropha oil, and castor oil also exhibited enhanced viscosity indices, pour points, and lubricities, which were comparable to the standards and commercial lubricants (Owuna et al., 2020). A flowchart of the transesterification procedure used to produce biolubricants is shown in Figure 3. Researchers investigated a variety of factors to produce a high yield and quality of biolubricant. The synthesized product was purified prior to formulation. In the case of TMPE as an additive, 
it was mixed with a base oil and submitted to a variety of assays to determine its performance. The baseline of a produced biolubricant is often compared to a standard grade and a commercially available biolubricant (Zulkifli et al., 2013). The flowchart for TMPE as a base oil or an additive in a biolubricant formulation is shown in Figure 4.

The properties of the stand-alone TMPE base stock are already superior as compared with most of other biodegradable synthetic esters. However, its lubricant performance could be further improved by formulation with other types of base oil and various additives technologies. With the same objective, the addition of TMPE to polyalphaolefin has reduced wear effectively (Zulkifli et al., 2013). The dispersion of nanoparticles in the synthetic ester base stock could potentially replace the conventional additives that could be harmful to the environment (Jason et al., 2020). Owing to the nano-sized solid particles, the asperities of the contacted surfaces could be filled. The addition of graphene nanoplatelets (GNP) in biolubricants, for example, is in line with the recent advances of nanotribology (Azman et al., 2016). Owing to nano solid's small size, the material can reach a constricted area for protective layering and bearing force during motion (Rashmi et al., 2017). Azman et al. (2016) proposed that only a small amount was required to prevent agglomeration behavior caused by particle interaction and forces at high concentration. Furthermore, an excess amount of GNP disrupts dispersion stability and increases the acidity of the oil. When large aggregates cannot fit in valleys between asperities, they may contribute to abrasive wear. Sufficient GNP aided in the formation of a protective layer for the prevention of asperities contact. Liñeira del Río et al. (2018) also investigated the performance of GNP in TMPE, as well as the speed of sound for pure oil and dispersions. The speed of sound values indicated the oil's quality in terms of chemical interaction between the pure oil and the nanoparticles. By forming thin protective graphene layers between rough surfaces, nanodispersants in oil were able to reduce the coefficient of friction. Because of TMPE's superior properties, less contentious additives such as ZDDP are added to the oil because it produces ash and poisonous emission during combustion (Hamdan et al., 2018).

Globally, regulations limiting the contents of hazardous additives such as sulfated ash, phosphorus, and sulfur have been implemented (Azman et al., 2016; Rashmi et al., 2017). These bearing additives could reversely affect the performance of devices, in particular diesel engines. Centers (1992) reported that a neurotoxin substance from lubricant decomposition may be produced at extreme temperature $\left(350-700^{\circ} \mathrm{C}\right)$. For turbine engine oil application that used synthetic oil, when trimethylolpropane and phosphorus from the additive combines during thermal combustion, trimethylolpropane phosphate was formed. In addition, the decomposition of trimethylolpropane ester roduced carboxylic acid (Kalman et al., 1985). Phosphorus was presented in anti-wear additives, such as tricresyl phosphate (TCP, which is from tritolyl phosphate isomers) (Centers, 1992).

\section{INDUSTRIAL APPLICATIONS OF BIOLUBRICANTS}

\section{Food Grade Biolubricant}

Leaks and maintenance of lubricants are inevitable in many industries. Thus, the food processing and pharmaceutical industries often face additional challenges, especially with the selection of the right lubricants. Food-grade lubricants must fulfill the same technical requirements as conventional lubricants. According to the United State Department of Agriculture (USDA), food grade lubricants are categorized into three groups: $\mathrm{H} 1, \mathrm{H} 2$, and $\mathrm{H} 3$. $\mathrm{H} 1$ is a food grade lubricant used in food processing industry; it is colorless, odorless, tasteless, and low hazard. $\mathrm{H} 2$ is a biolubricant that should not come into contact with food. Edible oils make up the H3 category and the feedstock is mostly derived from vegetable oils such as coconut, sunflower, canola, palm, palm kernel, soybean, rapeseed and jatropha oil, and cashew nuts (Bahadi et al., 2019; Bhaumik et al., 2019; Attia et al., 2020; Masripan et al., 2020). However, due to the limitations of vegetable oils, modifications to the chemical structures were made since vegetable oil remains the safest and most cost-effective raw material (Salih and Salimon, 2021). Agricultural and animal substances are subjected to a variety of processes in a manufacturing plant, including cleansing, mixing, cooking, canning, and packaging. Tanks, pumps, gears, mixers, chain drives, and conveyor belts in a large-scale food processing facility confront identical tribological and lubricating issues as non-food processing plant (Fitch et al., 2009). Food grade gear oils are ideal for lubricating drive chains, conveyor chains, gearboxes, and reduction units. Table 2 shows the commercially available food-grade gear oils from mineral, semisynthetic, and full synthetic. Full synthetic gear oil has excellent physicochemical properties, including a high viscosity index, kinematic viscosity at $100^{\circ} \mathrm{C}$, and the lowest pour point, $-43^{\circ} \mathrm{C}$.

Tribology of food grade lubricants can be improved by the modification of fatty acid structure, such as with the use of levulinic acid (LA). LA is feasibly produced from glucose, fructose, starch, and lignocelluloses residues and is widely used in a variety of applications, including food flavoring, composites, and fuel (Zhu et al., 2020). The esterification between TMP and LA produced a trimethylolpropane trilevulinic (TMP-tri-LA) ester with viscosity index, flash point, and pour point being $49,223^{\circ} \mathrm{C}$, and $-27^{\circ} \mathrm{C}$, respectively. As $10 \%$ of TMP-tri-LA was added to mineral oil, the WSD $(0.62 \mathrm{~mm})$ improved by $21 \%$ when compared with mineral oil alone $(0.78 \mathrm{~mm})$. TMP triester based on palm kernel fatty acids is also suited for a food processing machine (Bahadi et al., 2019). TMPTE with a viscosity index of 154 , a flash point of $320^{\circ} \mathrm{C}$, and a pour point of $-10^{\circ} \mathrm{C}$ were obtained (Bahadi et al., 2019). Di-trimethylolpropane tetraester (PKO-di-TMPTE) was proposed for food-grade hydraulic oil from the transesterification reaction of palm kernel oil and diTMP, with viscosity index, flash point, and pour point of 140.1, $392^{\circ} \mathrm{C}$, and $-6^{\circ} \mathrm{C}$, respectively (Bahadi et al., 2021). The 
TABLE 2 | Basic physicochemical properties of mineral oil, natural ester, and synthetic-based for food-grade gear oils.

\begin{tabular}{|c|c|c|c|c|}
\hline Test Parameter/ISO 220 & Method & Mineral-based & Synthetic ester & Natural ester \\
\hline Density at $20^{\circ} \mathrm{C}, \mathrm{kg} / \mathrm{l}$ & ASTM D 1298 & 0.89 & 0.844 & NA \\
\hline Kinematic viscosity at $40^{\circ} \mathrm{C}$, cSt & ASTM D 445 & 217 & $198 / 242$ & $198 / 242$ \\
\hline Kinematic viscosity at $100^{\circ} \mathrm{C}$, cSt & ASTM D 445 & 17.9 & 28.2 & 21.1 \\
\hline Viscosity index & ASTM D 2270 & 89 & 160 & 116 \\
\hline Flash point, ${ }^{\circ} \mathrm{C}$ & ASTM D 93 & 200 & 240 & 254 \\
\hline Pour point, ${ }^{\circ} \mathrm{C}$ & ASTM D 97 & -21 & -43 & -12 \\
\hline 4-Ball EP, weld point, min & ASTM D 4172 & NA & NA & 160 \\
\hline FZG test & DIN 5136 & NA & $>12$ & $>12$ \\
\hline Copper corrosion & ASTM D 130 & NA & $1 \mathrm{a}$ & $1 \mathrm{a}$ \\
\hline
\end{tabular}

NA: not available.

Mineral-based: H1 Quinplex ${ }^{\circledR}$ White Gear Oil.

Synthetic: Repsol FG, gear synth.

Natural ester: Repsol FG, Gear Industry (Semi synthetic).

TABLE 3 | Tribological improvement of food grade biolubricants.

Source of biolubricant

Major findings

Levulinic acid $(L A)+T M P+$ mineral oil

DiTMP esters

TMPE from crude palm kernel fatty acids

\begin{tabular}{lc}
\multicolumn{1}{c}{ Major findings } & References \\
\hline $\begin{array}{l}\text { Function: Biodegradable lubricant } \\
10 \% \text { of TMP-tri-LA in mineral oil improved } 21 \% \text { of WSD }(0.62 \mathrm{~mm})\end{array}$ & Zhu et al. (2020) \\
Exhibited the smallest WSD $(0.64 \mathrm{~mm})$ & Nowicki et al. (2019) \\
Up to $3450 \mathrm{~N}$ load for anti-seizure properties Thermally stable at $400^{\circ} \mathrm{C}$ & Bahadi et al. (2019) \\
Improvement in viscosity index compared to commercial ISO VG 46 &
\end{tabular}

TABLE 4 | Allowable composition of food grade additives in biolubricant.

\section{Additives}

Antioxidant

Anti-wear

Corrosion inhibitor

\section{Allowable composition}

References

Irganox L-57 (aromatic amine): 0.07-1 wt\%

BHT and Irganox 135 (phenolic): 0.3-1 wt\%

Phenolic to aromatic amine ratio: $4: 1$ or $1: 1$

Irgalube 349 (multifunctional): 0.1-1.0 wt\%

Irgalube TPPT: 0.3-1.0 wt\%

Antioxidant to anti-wear: $4: 1$ or $1: 1$

Sarkosyl O, Irgamet 39, Span 80: 0.05 to 1.0 wt\%
Alias et al. (2011)

Wolf, (1992)

Corbett et al. (2008) Wolf, (1992)

Corbett et al. (2008) Wolf, (1992) development of TMPE as a food grade biolubricant is summarized in Table 3.

Aside from producing oil with high lubricating capabilities, additives are utilized to compensate for the inadequacies of food grade lubricant. Food grade lubricant additives should adhere to the acceptable composition and be composed of safe chemicals compounds. In the event of accidental interaction with food products, the additives should not harm consumers' health. Antioxidant, anti-wear, and corrosion inhibitor are common additives. Antioxidants are required to inhibit the oxides derivatives. Sharma et al. (2007) stated that butylated hydroxyl toluene (BHT) is the second most effective antioxidant after zinc diamyl dithiocarbamate (ZDDC). BHT, a phenolic antioxidant, acts as a radical scavenger, preventing the phase of propagation. Furthermore, BHT is commercially available at a low cost and is HX-1 certified (Corbett et al., 2008). ZDDC acts as a peroxide decomposer and metal deactivator, preventing the commencement of the oxidation chain. To minimize environmental issues, heavy metal compounds such as lead, zinc, barium, and chlorine should not be used in lubricants (Waara et al., 2001; Zhan et al., 2004).

Irganox L-57, an aromatic amine type additive, has been approved by the Food and Drug Administration FDA/united States and can be used in food grade lubricants. It enhances antioxidant efficiency and can be used for long life span (Ciba, 2003). Wolf (1992) suggested that the best antioxidant ratio between phenolic and aromatic amine was 4 to 1 or 1 to 1 . However, at high concentrations, an aromatic amine additive may generate sludge. Another formulation consists of $0.3-1 \mathrm{wt} \%$ and 0.07 to $1 \mathrm{wt} \%$ for phenolic (for example BHT and Irganox 135) and aromatic amine additives, respectively. Sharma et al. (2007) stated that hindered phenols and diphenylamine demonstrated radical scavenger behavior and boosted oxidative stability at high temperatures. Alias et al. (2011) have documented Irganox 135 as an antioxidant in the hydraulic lubricating system with a $1 \mathrm{wt} \%$ composition did not improve WSD. Untreated oil oxidizes and thickens as a result of the polymerization process (Salih and Salimon, 2021). 
TABLE 5 | Basic physicochemical of mineral oil, natural ester, and synthetic ester for 10W-40 engine application.

\begin{tabular}{|c|c|c|c|c|}
\hline Test Parameter/10W-40 & Method & Mineral-based & Synthetic ester & Natural ester \\
\hline Density at $20^{\circ} \mathrm{C}, \mathrm{kg} / \mathrm{l}$ & ASTM D 1298 & 0.855 & 0.87 & 0.866 \\
\hline Kinematic viscosity at $40^{\circ} \mathrm{C}$, cSt & ASTM D 445 & 93.1 & 67.8 & 90.9 \\
\hline Kinematic viscosity at $100^{\circ} \mathrm{C}$, cSt & ASTM D 445 & 13.9 & 12.5 & 13.9 \\
\hline Viscosity index & ASTM D 2270 & 152 & 193 & 136 \\
\hline Flash point, ${ }^{\circ} \mathrm{C}$ & ASTM D 93 & 218 & 223 & 230 \\
\hline Pour point, ${ }^{\circ} \mathrm{C}$ & ASTM D 97 & -36 & -42 & -42 \\
\hline Base number, $\mathrm{mm} \mathrm{KOH/g}$ & ASTM D 2896 & 4.4 & NA & 8.25 \\
\hline Sulphated ash, wt\% & ASTM D 874 & 0.62 & NA & NA \\
\hline
\end{tabular}

NA: not available.

Mineral-based engine oil: Eurol Special 10W-40.

Fully synthetic-based engine oil: Chemlube Organic Ester-based Motor Oil.

Vegetable ester-based engine oil: Motul 300v 10 W40.

Previous research looked at the safe limit of additives in food grade lubricant as presented in Table 4 . There has been a limited study into the effect of food grade additives on TMPE for machinery application. Finally, the food grade lubricant should be nontoxic and nonhazardous to one's health. Aziz (2016) reported that an acute toxicity test might be performed to validate toxicity of a product. After 14 days of evaluation based on OECD Guideline 423, no adverse toxic response impact was observed for the administration of $2000 \mathrm{mg} / \mathrm{kg}$ body weight of pentaerythritol ester with anti-wear $(0.15 \%$ of Irgalube and $0.15 \%$ Irgalube TPPT) and corrosion inhibitor $(0.1 \%$ Irgamet 39) in Sprague-Dawley rats. Current toxicity testing covers advanced life stages of zebra fish (Danio rerio) (Poopal et al., 2020; van der Ven et al., 2020) and brine shrimp (Artemia salina) (Camargo et al., 2017; Rozaki et al., 2017).

Based from the previous findings, the use of TMPE in the formulation of food grade lubricants has successfully improved the physicochemical and tribological properties. TMPE that is a non-Newtonian shear-thinning and high viscosity index fluid reduces wear and friction between two moving parts. This is important to ensure the lubricant can provide a sufficient film thickness to protect the equipment or engine from wear. Selecting and applying high-quality food-grade biolubricants are critical elements in ensuring a safe working environment and hygienic processing facility.

\section{Engine Oil}

Engine oil is critical for protecting parts from excessive heat formation and preventing corrosion (Kotturu et al., 2020). Engine oil consumed $48 \%$ of world market application (Mobarak et al., 2014). The engine's operating conditions were divided into two categories: high-load and low-speed, and low-load and highspeed. In high-load and low-speed conditions, boundary friction dominates, whereas nonboundary friction governs in low-load and high-speed conditions. These two conditions were critical components of the endurance test, yielding useful results in terms of fuel consumption and wear loss at respective parts assigned. The viscosity index for engine oil should be greater than 90. EL-magly et al. (2018) stated that for gas turbine engine lubricants, their viscosity at $98.9^{\circ} \mathrm{C}$ and military or civil specifications must be abided to be listed as suitable base oil.
Based on various analyses, including kinematic viscosity, pour point, flash point, fire point, total acidity, and others, the study confirms that polyol ester performance was comparable to that of commercial lubricants (El-magly et al., 2018). Table 5 compares the physicochemical properties of commercially available products for engine application. All types of base oil have high viscosity index ranging from 152 to 193 . Diester's full synthetic ester-based product outperforms the viscosity of vegetable esterbased and mineral-based engine oil. Each product has a flash and pour point that is higher than $200^{\circ} \mathrm{C}$ and lower than $-30^{\circ} \mathrm{C}$.

Polyol ester-based engine oil, in particular TMPE, is a blooming and convincing base stock. Evolution of TMPE is observed to be utilized with commercial oil, and some research broadens to the addition of nano particles and surfactant to improve the lubricity of engine oils. Since 2002, TMPE has started to become an interesting subject and the effect of TMPE in poly alpha olefin (PAO) has been investigated by Rico et al. (2002). It was found that $5 \%$ of TMPE demonstrated the smallest wear scar for $264-490 \mathrm{~N}$ of loads. Pure TMPE recorded $0.533 \mathrm{~mm}$ of WSD and $0.612 \mathrm{~mm}$ for PAO. Rico et al. (2002) postulated that the lubricity of low polarity oil (such as PAO) was further improved with the presence of high-polarity TMPE. The findings of smaller WSD of $0.5 \mathrm{~mm}$ with $5 \%$ TMPE in PAO verified the function of TMPE as a wear reducer. Zulkifli et al. (2013) evaluated the efficacy of TMPE in a commercial oil (CO). The results highlighted that the addition of 3-7\% of TMPE in CO is enough for improved WSD and COF. $0.28 \mathrm{~mm}$ of WSD was obtained for the tested 3\% of TMPE in CO, compared with $0.36 \mathrm{~mm}$ of pure $\mathrm{CO}$, and $0.78 \mathrm{~mm}$ in pure TMPE. Severe abrasive wear was also reported in the study for pure TMPE. Reduction in COF increases the efficiency of machinery component and thus increases the lubricant and machine lifespan. Zulkifli et al. (2013) also stated that 3\% of TMPE acted as an active surface material and gave a sufficient protection layer on the rubbing surface contact. 7\% of TMPE exhibited the lowest friction torque $(0.02 \mathrm{Nm})$ up to $1569 \mathrm{~N}$ $(160 \mathrm{~kg})$. However, more addition of TMPE with fatty acids content may be added up to the corrosive acid accumulation during the oxidation process (Zulkifli et al., 2013).

Other studies on nonedible oil-based TMPE from Calopyllum inophyllum bring about interesting findings (Chebattina et al., 


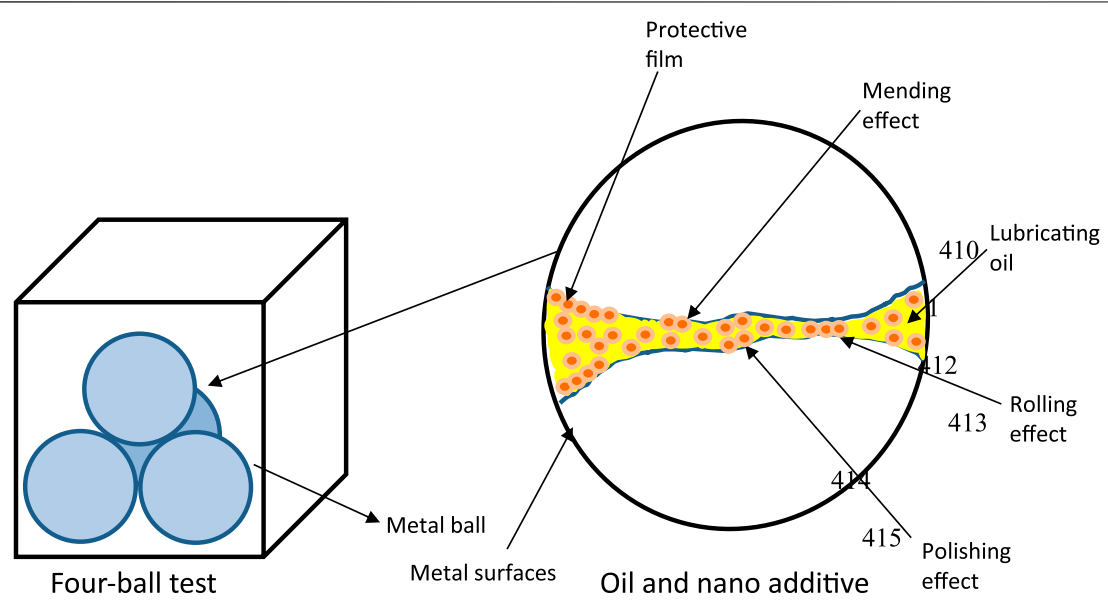

FIGURE 5 | Mechanism of nano additive between contacting surfaces (Shafi et al., 2018).

2019; Kotturu et al., 2020; Srinivas et al., 2020). When $20 \%$ of Calopyllum inophyllum-based TMPE was added to a commercial lubricant, higher WSD was observed than using only $10 \%$ of TMPE for $392 \mathrm{~N}$ of loads. Chebattina et al. (2019) obtained $428.23 \mu \mathrm{m}$ of WSD at $20 \%$ of TMPE, whereas Kotturu et al. (2020) and Srinivas et al. (2020) got 396.11 and $391.36 \mu \mathrm{m}$, respectively. Almost similar results obtained by the researchers proved that $10 \%$ was adequate to reduce wear and abrasion rate. The COF values were almost the same, around 0.0727 to 0.0788 . Srinivas et al. (2020) highlighted that the formulated engine oil could not bear higher than $785 \mathrm{~N}(80 \mathrm{~kg})$ of loads before the protection layer was completely broke down.

Nano additives have the potential to increase machine lifespan, reduce friction and wear, and thus improve the environment and reduce energy loss (Singh et al., 2020). The mechanisms of nano additives between contacting surfaces include rolling, mending, and polishing effects, as well as the formation of a protective film (Rapoport et al., 2002; Ali et al., 2018, 2019; Shafi et al., 2018; Kotia et al., 2020; Radhika et al., 2021). Figure 5 depicts the mechanism by which nano additives work.

$0.25 \%$ of graphene nano particles $(\mathrm{GnP})$ in TMPE gave the smallest WSD (48 nm) for $2.5 \mathrm{~N}$ load testing conducted by Liñeira del Río et al. (2018). The smallest COF, 0.105, was achieved at $0.5 \%$ of $\mathrm{GnP}$ in TMPE because of the thin protective graphene layer covering rough surfaces. The authors also suggested maintaining the $\mathrm{GnP}$ at smallest amount possible since high concentrations on $\mathrm{GnP}$ might increase the tendency of agglomeration which might worsen WSD (Liñeira del Río et al., 2018). In a different study, the addition of $0.05 \%$ of GnP together with 5\% of TMPE in PAO showed enhancement of $5 \%$ of COF (0.0737) and $15 \%$ of WSD $(0.42 \mathrm{~mm})$ (Azman et al., 2016). Rashmi et al. (2017) also investigated the effect of tribological properties on the addition of nano graphene platelets in TMPE base oil. At $392 \mathrm{~N}$ load, $0.1 \mathrm{wt} \%$ of $\mathrm{GnP}$ and $5 \%$ of phosphate ester reduced WSD by $16.2 \%$ compared with pure TMPE. This demonstrated that the GnP in the ester provided a stronger protective film that was resistant to oxidation attack. Based on $7 \%$ reduction in COF at $785 \mathrm{~N}$ load, a consistent film thickness that separated the metal surface from asperities was achieved. Yunus et al. (2020) thoroughly evaluated another intriguing combination of nano glass powder, palm oil, semisynthetic engine oil (commercial oil, CO), and TMPE. $0.5 \mathrm{wt} \%$ of nano glass powder in $70 \mathrm{wt} \%$ of $\mathrm{CO}$ and $30 \mathrm{wt} \%$ of esters ( $98 \%$ of palm oil and $2 \%$ of TMPE) use the high viscosity of $\mathrm{CO}$ to provide sufficient film thickness that separates metal surface in the engine at high temperature and loads. This combination simultaneously reduces the high viscosity of $\mathrm{CO}$, which is a disadvantage for additional friction. Additional friction caused by the viscosity of the oil can raise the COF. Because of their high viscosity index, esters served an essential purpose in improving viscosity-temperature behavior. This contributed to the formulations' stability. A minimum amount of nano glass powder was used because it could degrade the thermal stability of the blends. The lowest COF and WSD obtained were 0.057 and $295 \mu \mathrm{m}$, respectively. The findings were comparable to those of other studies (Yunus et al., 2020).

Gulzar et al. (2017) investigated the effect of nano particles size $\left[1 \%\right.$ of molybdenum disulphide $\left.\left(\mathrm{MoS}_{2}\right)\right]$ and surfactant (oleic acid) on wear protection in TMPE. The results were compared with the similar composition of nano particles and surfactant in commercial PAO. $\mathrm{MoS}_{2}$ was effective as anti-wear additives. It was found that surfactant increases the stabilization by the adsorption onto nano particles. Large size of nano particles $(50-2000 \mathrm{~nm})$ studied showed reduced agglomeration tendency than small size $(20-150 \mathrm{~nm})$. Without dispersant, large-size $\mathrm{GnP}$ was found to disperse better in oil than small size of GnP. The addition of surfactant promoted better suspension in both GnPs sizes. Higher average improvement $14.28 \%, 37.5$, and $25 \%$ was observed for formulated TMPE to pure oil, than formulated PAO to its pure oil in terms of last non-seizure load (LNSL), initial seizure load (ISL), and weld point (WP), respectively. Mean WSD at ISL $2.48 \mathrm{~mm}$ for small GnP size, $2.66 \mathrm{~mm}$ for large size of $\mathrm{GnP}$ were achieved for formulated TMPE where pure TMPE yielded $2.68 \mathrm{~mm}$ of WSD. Nano particles tend to 
TABLE 6 | Tribology properties of TMPE-based engine oil.

\section{Source of biolubricant}

TMPE + Poly alpha olefin (PAO)

Palm-based TMPE + Commercial oil (CO)

Calopyllum inophyllum-based TMPE + CO

Calopyllum inophyllum-based TMPE + CO

Calopyllum inophyllum-based TMPE + CO

TMPE + GNP

Palm-based TMPE + PAO + graphene nanoplatelets (GNP)

Palm-based TMPE + GNP + Phosphate ester (PE)

Palm-based TMPE + Palm oil + nanoglass

Palm-based TMPE + Molybdenum disulfide $\left(\mathrm{MoS}_{2}\right)$ nano particle + surfactant (oleic acid)

\section{Major findings}

$5 \%$ of TMPE in PAO exhibits best wear performance under load (264-490 N)

$3 \%$ of TMPE reduces $30 \%$ of COF $(0.05)$ and WSD $(0.28 \mathrm{~mm})$

$7 \%$ of TMPE gives lowest friction torque $(0.02 \mathrm{Nm})$

$20 \%$ of TMPE in CO shows the best result of smallest COF $(0.0727)$ and

$428.23 \mu \mathrm{m}$ of WSD for $392 \mathrm{~N}$ load

$10 \%$ of TMPE in CO provides sufficient protection layer for the smallest WSD

(396.11 $\mu \mathrm{m}$ for $392 \mathrm{~N}, 485.11 \mu \mathrm{m}$ for $588 \mathrm{~N}$ ) and COF (0.0788)

$10 \%$ of TMPE in CO yields 391.36 and $467.62 \mu \mathrm{m}$ of WSD for 392 and $589 \mathrm{~N}$ load, respectively. The formulation gave small COF but failed at $785 \mathrm{~N}$

$0.25 \%$ GNP in TMPE produced the minimum wear width (48 nm)

$0.5 \%$ GNP in TMPE provided the lowest COF $(0.105)(2.5 \mathrm{~N})$

$5 \%$ of TMPE in $95 \%$ of PAO and $0.05 \%$ GnP improves $5 \%$ of COF $(0.0737)$ and

$15 \%$ of WSD $(0.42 \mathrm{~mm})$

$5 \%$ of PE and $0.1 \%$ of GNP gave $16.2 \%$ reduction in WSD (0.34 mm for $392 \mathrm{~N}$ Rashmi et al. (2017) load)

$6.9 \%$ reduction of COF $(0.48$ for $785 \mathrm{~N})$ was achieved

0.5\% nanoglass $+30 \%$ (98\% Palm oil $+2 \%$ TMPE) $+70 \%$ CO achieved $33 \%$ of Yunus et al. (2020)

WSD $(295 \mu \mathrm{m})$ reduction and improved $40 \%$ of COF $(0.057)$

$1 \mathrm{wt} \%$ of $\mathrm{MoS}_{2}$ and $1 \mathrm{wt} \%$ of surfactant in TMPE

Mean WSD at ISL $2.48 \mathrm{~mm}$ for small GnP size

\section{References}

Rico et al. (2002)

Zulkifli et al. (2013)

Chebattina et al

(2019)

Kotturu et al. (2020)

Srinivas et al. (2020)

Liñeira del Río et al. (2018)

Azman et al. (2016)
Gulzar et al. (2017)

$2.66 \mathrm{~mm}$ for large size of GnP. Pure TMPE yielded $2.68 \mathrm{~mm}$ of WSD.

TABLE 7 | Basic physicochemical and dielectric properties of mineral oil, natural ester, and synthetic ester.

\begin{tabular}{|c|c|c|c|c|c|}
\hline & Units & IEC 61099 specification $^{a}$ & Mineral oil & Natural ester & Synthetic ester \\
\hline Kinematic viscosity at $40^{\circ} \mathrm{C}$ & $\mathrm{mm}^{2} / \mathrm{s}$ & $<35$ & 8 & 36 & 24 \\
\hline Flash point & ${ }^{\circ} \mathrm{C}$ & $\geq 250$ & 150 & 316 & 260 \\
\hline Pour point & ${ }^{\circ} \mathrm{C}$ & $\leq-45$ & -50 & -21 & -60 \\
\hline Acidity & $\mathrm{mg} \mathrm{KOH} / \mathrm{g}$ oil & $<0.03$ & 0.001 & & \\
\hline Moisture content & ppm & $<200$ & 2.4 & & \\
\hline Biodegradability & $\%$ & & 10 & 97 & 89 \\
\hline Breakdown voltage (2.5 mm gap) & $\mathrm{kV}$ & $>45$ & 70 & $>75$ & $>75$ \\
\hline Dielectric dissipation factor (tan $\boldsymbol{\delta}$ at $\left.90^{\circ} \mathrm{C}\right)$ & - & $<0.03$ & $<0.002$ & $<0.003$ & $<0.008$ \\
\hline Permittivity & - & $\mathrm{N} / \mathrm{A}^{\mathrm{b}}$ & 2.2 & 3.1 & 3.2 \\
\hline
\end{tabular}

${ }^{a}$ IEC, 61099 - Insulating liquids - Specifications for unused synthetic organic esters for electrical purposes.

${ }^{b} \mathrm{~N} / \mathrm{A}-$ not available.

cover the rubbing surfaces and make up for the worn surfaces. Thus, GnP attends and polishes the interacting surfaces simultaneously (Gulzar et al., 2017). Table 6 summarizes the development of TMPE as an engine oil.

Addition of $3-20 \%$ of TMPE in various synthetic stocks has been evaluated. Researchers agreed in unison that TMPE does have a wear reducer effect. Improvement of the COF efficacy denotes that lubricant and machine usage could be prolonged. However, the fatty acids content in vegetable oils-based TMPE is a concern due to corrosive acids that may be produced during the machine or engine operations. The advances of nano particles in engine oil have broader prospect in engine applications. As most of the research extensively study on the tribological aspects from WSD and COF point of view, the hydrolytic, thermal, and oxidative stability in engine applications should be investigated in depth.

\section{Transformer Insulating Liquid}

Another major growth area for TMPE over the last 2 decades has been in environmentally acceptable insulating liquids. Mineral-based transformer insulating liquid has long served the purposes of insulating and cooling in an electrical power transformer. In recent years, substantial efforts have been explored to develop high-performance eco-friendly insulating liquids to replace mineral oil. Polychlorinated biphenyl (PCB)-based insulating liquids were once marketed for high fire safety requirements but were outlawed in the 1970s due to the health and environmental risks (Fofana, 2013). The phasing out of a PCB led to development of other halogenated insulating fluids, such as benzyltoluene, perchorethylene, trichlorobenzene, and dichlorotoluene, which are considered nonflammable. "Less flammable" insulating liquids have been established for transformers at major fire risk locations and are primarily high molecular weight hydrocarbons, silicone oil, synthetic esters, and natural (vegetable) esters (McShane et al., 1999). Table 7 compared the basic parameters for fresh mineral oil, natural ester, and synthetic ester to the IEC 61099 specifications.

As tabulated in Table 8, there are several studies in the literature reporting the application of TMPE as the insulating liquids (Kanoh et al., 2008; Kanoh et al., 2012; Hof et al., 2008; 
TABLE 8 | Previous studies on the application of TMPE as a transformer-insulating liquid.

\begin{tabular}{|c|c|c|c|c|c|c|c|c|c|}
\hline References & Fatty acid & $\begin{array}{l}\text { Flash } \\
\text { point } \\
\left({ }^{\circ} \mathrm{C}\right)\end{array}$ & $\begin{array}{l}\text { Pour } \\
\text { point } \\
\left({ }^{\circ} \mathrm{C}\right)\end{array}$ & $\begin{array}{l}\text { Viscosity } \\
\left(\mathrm{mm}^{2} / \mathrm{s}\right)\end{array}$ & $\begin{array}{c}\text { Acidity (mg } \\
\text { KOH/g } \\
\text { of oil) }\end{array}$ & $\begin{array}{l}\text { Moisture } \\
\text { content } \\
\text { (ppm) }\end{array}$ & $\begin{array}{l}\text { Breakdown } \\
\text { voltage (kV) }\end{array}$ & $\begin{array}{c}\text { Tan } \delta \text { Permittivity } \\
\text { Resistivity } \\
(\Omega \mathrm{cm})\end{array}$ & $\begin{array}{c}\text { Oxidation } \\
\text { stability }\end{array}$ \\
\hline Wang et al. (2019) & $\begin{array}{l}\text { C6, C8 and C10 } \\
\text { blend (coconut } \\
\text { and castor) }\end{array}$ & 248 & -45 & 23.3 & 0.028 & $\mathrm{~N} / \mathrm{A}$ & $\begin{array}{c}72.6(2.5 \mathrm{~mm} \\
\text { spacing })\end{array}$ & $\begin{array}{c}0.02 \\
3.2 \\
10^{13}\end{array}$ & $\begin{array}{l}\text { OlT at } \\
130^{\circ} \mathrm{C}: 38 \mathrm{~h}\end{array}$ \\
\hline $\begin{array}{l}\text { Capuzzi et al. } \\
\text { (2019) }\end{array}$ & $\mathrm{C} 9$ and C10 & 220 & -54 & 21.4 & 0.01 & 46.7 & 86 & $\begin{array}{l}0.03 \\
\mathrm{~N} / \mathrm{A} \\
6.3^{12}\end{array}$ & $\mathrm{~N} / \mathrm{A}$ \\
\hline $\begin{array}{l}\text { Raof et al. } \\
\text { (2019b); Raof } \\
\text { et al. (2019a) }\end{array}$ & C18:1 (palm oil) & 310 & -18 & 42.5 & 0.084 & 146 & 95 & $\begin{array}{c}0.01 \\
2.8 \\
2.4^{13}\end{array}$ & $\begin{array}{l}435^{\circ} \mathrm{C} \text { (TGA } \\
\text { onset } \\
\text { temperature) }\end{array}$ \\
\hline $\begin{array}{l}\text { Qiu and Brown } \\
\text { (2013) }\end{array}$ & C18:1 (soybean) & 318 & -38 & 41.8 & 0.015 & 25 & $N / A$ & $\begin{array}{l}\text { N/A } \\
0.9 \\
6^{13}\end{array}$ & $\begin{array}{l}\text { OSI at } \\
110^{\circ} \mathrm{C}: 14 \mathrm{~h}\end{array}$ \\
\hline Hof et al. (2008) & C5 to C11 & 273 & -49 & 19.3 & 0.01 & 100 & $\begin{array}{c}75 \text { (2.5 mm } \\
\text { spacing) }\end{array}$ & $\begin{array}{l}0.025 \\
\mathrm{~N} / \mathrm{A} \\
8.3^{13}\end{array}$ & $\mathrm{~N} / \mathrm{A}$ \\
\hline
\end{tabular}

N/A: not available.

Qiu and Brown, 2013; Raof et al., 2016). TMPEs produced from saturated fatty acids of $\mathrm{C} 5$ to $\mathrm{C} 11$ have been patented by Hof et al. (2008) and claimed to satisfy all requirements for transformer oil. The ester produced exhibited excellent properties of transformer oil, such as low viscosity and low pour point as well as excellent oxidation and dielectric properties. The reported biodegradability corresponds to "readily biodegradable" limit (more than $60 \%$ $\mathrm{BOD} / \mathrm{COD}$ or $\mathrm{CO} 2$ evolution or $>70 \%$ DOC removal after 28 days). They incorporated $0.1 w t \%$ of antioxidants (preferably BHT or phenyl naphthylamines or diphenylamines) and $0.1 \mathrm{wt} \%$ of metal deactivator (preferably triazoles or tolyltriazoles or dimercaptothiadiazolines).

In a different study, Qiu and Brown (2013) synthesized TMPE from high-oleic soybean oil and showed remarkable insulating properties such as high flash point and low moisture content. However, the major drawback of this invention was its very low oxidative stability index (OSI) compared to Midel 7131. The reported OSI at $110^{\circ} \mathrm{C}$ for high-oleic TMPE and Midel 7131 were 14 and $>100 \mathrm{~h}$, respectively. It was suspected that the low OSI is the result of the high content of linoleic and linolenic fatty acid content in the soybean oil. Capuzzi et al. (2019) invented a low pour point TMPE particularly for insulating oils in the electrical equipment that requires an effective cooling action. They exceptionally found that the addition of about $10 \%$ of branched C9 acids (3,5,5trimethylhexanoic acid) to linear C9 monocarboxylic acids (nonanoic acid) brings about an appreciable fall of pour point to less than $-50^{\circ} \mathrm{C}$. To minimize the acidity and water content, the TMPE product was purified further using Fuller's earth (sepiolite) and A4 molecular sieves. They also discovered the slight reduction in water content, acidity, and dielectric loss with the addition of $0.3 \mathrm{wt} \%$ of primary phenol antioxidant (Irganox ${ }^{\circledR} 1010$, marketed by BASF SE) (Capuzzi et al., 2019).

In three reports by our group (Raof et al., 2019b; Raof et al., 2019a; Raof et al., 2019c), the high oleic TMPE was synthesized from palm oil methyl ester. We studied the effect of molecular structure on the physicochemical and electrical properties in detail. We found that the palm-based TMPE has a superior flash point compared to PFAE, mineral oil, and some other esters. In terms of electrical properties, TMPE exhibited excellent breakdown voltage, relative permittivity, dissipation factor, and resistivity. The only drawbacks of this ester are its physical properties such as high viscosity and pour point which does not conform to the IEC standard. Thus, in a different study, we blend the TMPE with mineral oil and 80\%/20\% blend (TMPE/mineral oil) was found to be promising with properties nearest to the standard values for transformer liquid insulation (Raof et al., 2019c). The blend provides significant benefits to utilities in terms of improved fire safety, biodegradability, and performance properties. Most importantly, the blend can reduce the oxidization issues associated with copper/steel corrosion caused by conventional mineral oil.

Wang et al. (2019) synthesized TMPE by the esterification of the mixture of C6, C8, and C10 acids blend with TMP alcohol. High-performance TMPE was prepared using a purification method that included washing with ultrapure water and absorption with a molecular sieve. The ester was washed with ultrapure water to reduce the ionic and polar impurities. Then the molecular sieve was added to reduce the moisture content and the product was further filtered and dried. Although the electrical properties improved significantly during the purification processes, it is not economical and would impair future mass production significantly. Recently, the same group of researchers found a new purification method for the mass production of TMPE. The addition of $3 \mathrm{wt} \%$ alkaline $\mathrm{Al}_{2} \mathrm{O}_{3}$ and $5 \mathrm{wt} \%$ activated clay as adsorbents managed to reduce more than $80 \%$ of acidity and dielectric loss (Wang $\mathrm{K}$ et al., 2020). Alkaline $\mathrm{Al}_{2} \mathrm{O}_{3}$ successfully reduce the acidity to $0.028 \mathrm{mg} \mathrm{KOH} / \mathrm{g}$. After subjected to absorption with $5 \%$ of activated clay (at $90-95^{\circ} \mathrm{C}$ and $0.2-0.6 \mathrm{kPa}$ for $30 \mathrm{~min}$ ) and multiple filtrations, the dielectric loss $(\tan \delta)$ decreases and resistivity increases significantly. Wang $\mathrm{X}$ et al. (2020) also proposed that additives that do not contain oxygen, fluorine, or chlorine should be prioritized when formulated with TMPE. These negative ions would greatly 
TABLE 9 | Previous studies on the application of TMPE as a biodegradable hydraulic fluid.

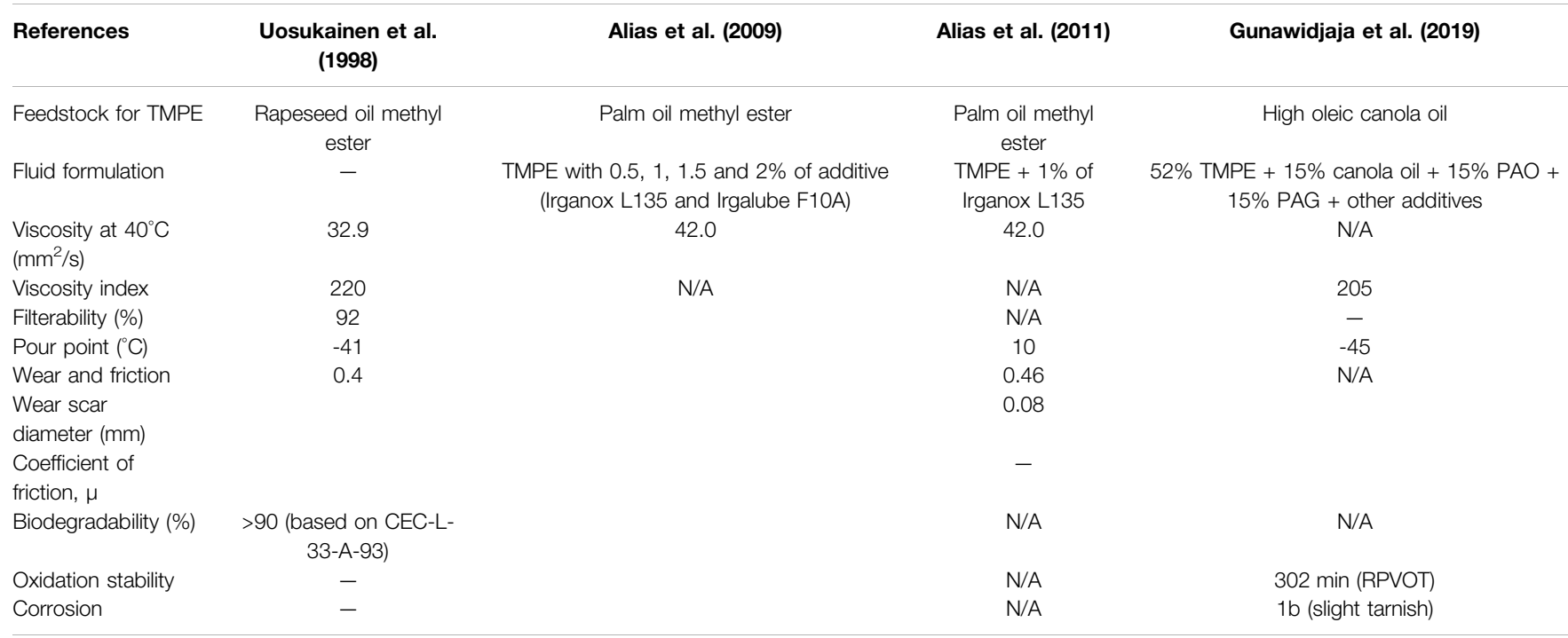

induce space charges in electric fields and increase the streamer propagations. A shift to renewable and biodegradable fluids requires a greater need for new effective additives to meet the challenges of formulating insulating fluids for transformer applications. Given that impulse pre-breakdown and breakdown characteristics are linked to the chemical composition of the liquid, the use of esters (which have a different chemical composition than mineral oil) requires a detailed study under impulse voltage (Rozga et al., 2020).

\section{Hydraulic Fluid}

Environmentally friendly hydraulic fluid is another important development area for TMPE in biolubricant application. Hydraulic fluids transfer power to the moving parts of many machines, including automobiles, bulldozers, tractors, and the majority of heavy construction equipment (Mendoza et al., 2011). Therefore, they must meet particular specifications in order for the machines to function properly. A good hydraulic fluid should have the following properties: low loss power transmission, lubrication of moving surfaces, oxidation resistance, tribological and anticorrosion properties, compressibility, compatibility with seal, etc. (Alias et al., 2009). The vegetablebased hydraulic fluids suffer several issues mainly related to oxidative stability, incompatibility with bearing materials, low friction torque, and low temperature properties (Syahrullail et al., 2013). Under extreme loads, vegetable oil also loses its effectiveness.

The useful lives of the hydraulic fluids can be extended by the use of higher oleic oils and appropriate additives. In a report by Akerman et al. (2011), the high conversion to high oleic TMP triester (with low diester and monoester contents) is important to fulfill the required pour point for hydraulic fluids requirements. The transesterification of rapeseed oil methyl ester with TMP which was performed by Uosukainen et al. (1998) exhibited good cold stability, friction and wear characteristics, and resistance against oxidation at elevated temperatures. The TMPE prepared in their work had a viscosity grade of 32 , and contained (w/w) $0.5-2.5 \%$ antioxidant, $1.0-5.0 \%$ pour-point depressor, $0.4-2.0 \%$ antiwear agent, and $0.1-0.5 \%$ antifoam agent.

Gunawidjaja et al. (2019) studied the effect of adding PAO and PAG in the formulation containing TMPE derived from high oleic canola oil as the base stock. PAO significantly increases the oxidative stability and maintains a low pour point, but it has an adverse effect on hydrolytic stability. PAG improves the hydrolytic stability and slightly increases the oxidative stability, but undesirably increases the pour point. The synergistic interaction between PAO, PAG, and TMPE (with other additives) managed to produce hydraulic fluids with a high viscosity index, a low pour point, and a good hydrolytic and high oxidative stability (Gunawidjaja et al., 2019).

To study the oxidative stability and wear properties of hydraulic fluid formulation, the "Lab-scale Hydraulic Test Rig" was developed by a group of researchers from UPM (Alias et al., 2009). The performance of palm-oil-based TMPE was studied at temperature range of $80-100^{\circ} \mathrm{C}$ for $800 \mathrm{~h}$ (without and with the presence of additives) while monitoring the changes in acidity and oil viscosity. The results revealed that Irganox L135 additive outperforms Irgalube F10A additive. The ultimate TAN value for the formulated oil was just $0.32 \mathrm{mg} \mathrm{KOH} / \mathrm{g}$ after $800 \mathrm{~h}$ of exposure, compared to $4.88 \mathrm{mg} \mathrm{KOH} / \mathrm{g}$ for the oil without addition. The findings suggest the compatibility of TMPE with Irganox L135 as an antioxidant and this is a great contribution to the future studies involving the formulation of TMPE as a biolubricant base stock. Similar authors then conducted wear and friction test to the TMPE formulation with 1\% of Irganox L135 and found reduction in coefficient of friction (from 0.08 to 0.06) compared to the unadditived TMPE base oil (Alias et al., 2011). However, the formulated TMPE exhibited quite high WSD compared to the unadditived TMPE and this suggests further addition of anti-wear additive to improve the formulation. Table 9 summarizes the previous studies that involved in the 
application of TMPE as hydraulic fluids. TMPE found its application as a hydraulic fluid due to its improved oxidative stability, viscosity index, and tribological properties. Hydraulic fluids, like any other application, must be carefully designed with additives to protect the base stock and components in the hydraulic system while also ensuring optimum system performance.

\section{Heat Transfer Fluid}

Heat transfer fluid, also known as thermal fluid, is a heat transmission fluid with excellent oxidation resistance. It is used for cooling or heating or as a thermal storing medium in a process heating, metal working, and machine cooling applications. Water is naturally an efficient heat transfer medium; but, due to its processing temperature and pressure limits, water is no longer practical (Qazi, 2017). Water can also create corrosion on the system piping, which is a disadvantage. The heat of vaporization, thermal conductivity, and specific heat are the design parameters in every heat transfer fluid. A reduction in the heat transfer would result in the reduction of energy efficiency. There are several types of heat transfer fluids available which include refrigerants, anti-freezes, chiller fluids, hot oils, etc. The main synthetic fluids are ester and diester compounds, polyglycol and water-glycol fluids, and siliconebased greases and oils. The thermal conductivity of TMPE and other esters are slightly higher than hydrocarbons, therefore improving the heat transfer properties of the oils (Shah et al., 2021).

More stringent emission rules, the need to minimize oil dependency, and the need to increase transportation energy efficiency are all driving the increasing interest in the application of ester in electric vehicle technology. The main challenge associated with the electric vehicles is the optimization of the thermal management system which requires efficient cooling and heating methods. To avoid breakdown, the system must be able to maintain a steady temperature across the operational temperature range of components such as the battery. Despite the fact that the water/glycol mixture has outstanding heat transfer capabilities, its high electrical conductivity may cause electivity leakage and power losses in the fluid. Among other factors, the diester and trimester-based heat transfer fluid provides a heat transfer fluid that is biodegradable and environmentally friendly, has low flammability, and is therefore safe. The application of triester as a heat transfer fluid in the electric vehicles is described in United States 2012/0164506 A1 Patent by Claeys et al. (2012). The ester was derived from a mono-unsaturated fatty acid and biomass. The coolant exhibits an electrical volume resistivity at $25^{\circ} \mathrm{C}$ of at least $10^{10} \Omega-\mathrm{cm}$, and generally at least $10^{12} \Omega-\mathrm{cm}$. The specific heat of the present coolantas exhibited at $20^{\circ} \mathrm{C}$ is generally at least $2.00 \mathrm{~kJ} / \mathrm{kg}$.K., and can be at least $2.30 \mathrm{~kJ} / \mathrm{kg} . \mathrm{K}$. The present coolant composition also generally exhibits a thermal conductivity at $20^{\circ} \mathrm{C}$. of at least $0.170 \mathrm{~W} / \mathrm{m} . \mathrm{K}$., and even at least $0.200 \mathrm{~W} / \mathrm{m} . \mathrm{K}$. The ester samples have electrical resistivities significantly higher than the water/glycol mixtures and the magnitude of the electrical resistivity is of the order that it
TABLE 10 | Comparison of properties of trimethylolpropane ester (TMPE) and mineral oil as MWF (Benedicto et al., 2017).

\begin{tabular}{lll}
\hline Performance & TMPE & Mineral oil \\
\hline Biodegradability & Better & Poor \\
Toxicity & Low & High \\
Oxidative stability & Moderate & Better \\
Lubrication & Better & Good \\
Heat exchange & Good & Good \\
Viscosity index & Better & Moderate \\
Hydrolytic stability & Moderate & Very good \\
Thermal stability & Good & Good \\
Seal compatibility & Moderate & Better \\
Relative cost to mineral oil & 2 & 1 \\
\hline
\end{tabular}

can be used as a dielectric fluid in applications with low conductive requirements (Claeys et al., 2012).

In a different study, United States Patent United States5494597A discloses refrigeration working fluids made of TMPE which is prepared from branched C7 to C10 monocarboxylic acids (Krevalis et al., 1996). This carbon chain length is said to produce satisfactory miscibility values, when admixed with the R152a and R125 refrigerants compared with other higher or lower alkyl carbon chain length. For instance, the formulation of 10wt\% iso-decanoic/TMP (acid/polyol) and $90 \mathrm{wt}$ $\%$ of $\mathrm{R} 152 \mathrm{a}$ resulted in a viscosity of $46.8 \mathrm{~mm} 2 / \mathrm{s}$ and $-60^{\circ} \mathrm{C}$ miscibility value. The patent also mentioned to avoid the use of esters with lower carbon chain length (C2 to $\mathrm{C} 6)$ since they are more volatile, more hydrophilic and exhibit more solvation power. These are all the undesired properties in the formulation of good refrigeration working fluids (Krevalis et al., 1996).

\section{Metal Working Fluid}

In metal working fluids (MWF), fatty acid esters have found application as a lubricant additive and TMPE is the most common ester used (Mathiesen, 1998). MWF plays a crucial role as a cutting fluid in machining to facilitate lubrication by providing a thin layer between interfaces of metal working tools and work pieces. It also acts as a coolant to reduce heat of tools and pieces for an optimum efficiency and productivity. Continuous efforts in developing a sustainable plant oil-based MWF have been done to replace the hazardous mineral oilbased MWF. It was due to an evaluation result in 1987 by International Agency for Research on Cancer that has determined the conventional MWF as a carcinogen ( $\mathrm{Li}$ et al., 2003). Hence, for an environmentally friendly and sustainable machining process, a combination of low toxicity, biodegradable lubricant, dry machining, and minimum quantity lubrication (MQL) conditions are required (Talib and Rahim, 2016).

Investigations on tribology characteristic and metal working process have revealed the potential of TMPE to replace mineral oil as MWF, as summarized in Table 10. Long polar fatty acid chains of plant oil-based TMPE (C16 to C18) have contributed to a strong, thin, and sufficient lubrication on the contact surfaces, which was also great in adsorption on the metal surfaces (Talib 
TABLE 11 | Additives related to MWFs.

\begin{tabular}{|c|c|c|}
\hline Additive type & Function & Chemical compounds \\
\hline $\begin{array}{l}\text { Anti-aging additive, oxidation } \\
\text { inhibitor }\end{array}$ & Prevention of oxidation of base oil at high temperatures and stabilization & $\begin{array}{l}\text { Aromatic amines, organic sulfide, zinc } \\
\text { dialkyldithiophosphate }\end{array}$ \\
\hline Anti-wear additive & Reduction of abrasive wear of rubbing surfaces by physisorption & $\begin{array}{l}\text { Acid and nonionic phosphoric acid ester, zinc dialkyldithio- } \\
\text { phosphate }\end{array}$ \\
\hline Biocides & Prevention of excessive microbial growth & $\begin{array}{l}\text { Phenol derivatives, formaldehyde releasers, } \\
\text { isothiazolinones }\end{array}$ \\
\hline Dispersant & $\begin{array}{l}\text { Prevention of varnishes build-up on surfaces and agglomeration of particles to } \\
\text { form solid deposit }\end{array}$ & Sulfonate, phenolate, salicylate \\
\hline Emulsifier & Emulsion formation and stabilization & $\begin{array}{l}\text { Anionic sulfonates, potassium-soap, alkanolamine-soap, } \\
\text { nonionic fatty alcohol }\end{array}$ \\
\hline Extreme pressure additive & $\begin{array}{l}\text { Protection against wear by formation of adsorption or reaction layers, prevents } \\
\text { micro fusing of metallic surfaces }\end{array}$ & $\begin{array}{l}\text { Chlorineparaffine, sulphuros ester, phosphoric acid, ester, } \\
\text { polysulfide }\end{array}$ \\
\hline Foam inhibitor & Destabilization of foam in oil & Silicone polymers, tributyl phosphate \\
\hline Friction modifier & Friction and wear reduction, enhancement of lubricating film adhesion & Glycerol mono oleate, natural fats, synthetic ester \\
\hline Metal-deactivators & Adsorptive film formation & Heterocycles, di-amine, triaryl phosphite \\
\hline
\end{tabular}

References (Lawal et al., 2012; Brinksmeier et al., 2015; Wickramasinghe et al., 2020).

and Rahim, 2014). Furthermore, its high viscosity has produced low WSD and COF, which also reduced the vaporization volume as compared with a commercial synthetic ester (Talib and Rahim, 2014).

The tribology characteristic as well as physicochemical properties of TMPE can be further improved with the formulation of MWFs in which the surfactants and additives modify the chemical structure to withstand special environmental conditions for better performance. The additives and surfactants as listed in Table 11, in the range of $5-15 \%$, could be added to improve seal compatibility, oxidative and hydrolytic stabilities as shown in comparison of TMPE and mineral oil MWFs (Wickramasinghe et al., 2020). An evaluation on machining process with an MQL technique was carried out by using Jatropha oil-based TMPE, or modified Jatropha oil (MJO), with an addition of $0.05 \mathrm{wt} \%$ hexagonal boron nitride (hBN) nanoparticle (Talib et al., 2019). MJO with $0.05 \mathrm{wt} \% \mathrm{hBN}$ had the lowest cutting force $(383 \mathrm{~N})$ and cutting temperature $\left(210^{\circ} \mathrm{C}\right)$ as compared with the pure MJO and synthetic mineral oil MWFs. Moreover, the addition of nanoparticle to the MJO also greatly reduced tool-chip contact length on the cutting inserts.

An application of the plant oil-based TMPE with miscible ionic liquids additives via the MQL technique could also greatly reduce excessive usage of MWF, as studied by Abdul Sani et al. (2019). The additions of fully oil-miscible and biocompatible ionic liquids, $10 \%(\mathrm{~N} 1,8,8,8)$ (NTf2) (AIL) with MJO as the base oil and $1 \%(\mathrm{P} 6,6,6,14)$ [ i (C8)2PO2] (PIL) with MJO showed the highest cutting performance and required low specific cutting energies. They have successfully reduced cutting forces and specific cutting energy by $4-5 \%$, cutting temperatures by $7-10 \%$, friction coefficient by $2-3 \%$, tool-chip contact length by $8-11 \%$, chip thickness by $22-25 \%$, friction angle by $1-2 \%$ and increased shear angle by $25-29 \%$ compared to the benchmark synthetic ester lubricant. Hence, the study revealed the highly potential and sustainable green alternative to the mineral oilbased MWF.

An adaptability and performance of formulation of high oleic palm oil-based TMPE (HO-TMPE) with different additives was also investigated by Chang et al. (2015), specifically for the tapping oil formulations. The research study revealed that the formulation of $88.8 \% \mathrm{HO}-\mathrm{TMPE}$ base oil with $5 \%$ high molecular polymer ester GY$25,1 \%$ alkyl phosphate 360-P (extreme pressure, EP and anti-wear AW), and 5\% L5333 (a sulfurized vegetable oil with 10 wt $\%$ active sulfur as a lubricity improver) and $0.2 \%$ KSP-93 (triazole derivative as a metal passivator) additives, had potential as MWF for heavy-duty applications in hard metals such as stainless steel, duplex stainless steel, and hastealloy ${ }^{\circledR}$. Other research studies that had used high oleic palm oil-based TMPE with synergy of additives such as nanoparticles and ionic liquids also revealed its technological competitiveness and commercially viable MWF (Sani et al., 2017; Kathamore and Bachchhav, 2021).

\section{Drilling Fluid}

In drilling fluid application, TMPE was examined as an additive, specifically, as a nonionic surfactant, along with other potential polyol esters such as neopentyl glycol ester (NPGE) and pentaerythritol ester (PEE) (Kania et al., 2021). The polyol esters act as a thinner to prevent flocculation of uncharged macro-molecules and finally to stabilize the colloidal particles (Napper, 1977; Luckham and Rossi, 1999). It was found that by using Monte-Carlo and Molecular descriptor calculations, polyol esters with more hydrophobic fatty acid chains had high possibility to enhance rheology of drilling fluids and stability of mud emulsions. Moreover, the hydrophobic chains in TMPE provide the affinity to attract molecules on the organoclay and its high molecular mass also contributes to a maximum adsorption density. Hence, TMPE with three hydrophobic chains is suitable as a drilling mud with moderate solid content, as compared with PEE that has four hydrophobic chains that is more apt for high solid-content mud (Kania et al., 2018; Kania et al., 2021).

\section{PROSPECTS AND CHALLENGES}

Modern machine and engine advancements have presented numerous challenges in terms of the effectiveness and 
performance of current biolubricant base oils and formulations. Some of the challenges include the need for more cost-effective production plant, the need to reduce the dependence on the current plant oil feedstocks, the specialized performance requirements of emerging end-use applications, and many more (Rudnick, 2017). Development of biodegradable fluids with the necessary high oxidative and thermal stability has been a major challenge for the industry. Synthetic ester, particularly TMPE, often defines the maximum performance in terms of thermal and oxidative stability due to the absence of beta hydrogens in its structures (Frauscher et al., 2017; Rudnick, 2017). However, like any other organic compounds, the oxidative stability of TMPE can be compromised. Previous studies have reported that the degradation of TMPE is significantly enhanced by catalytic surface reactions by several dissolved metals, including copper, iron, and zinc (Kauffman, 2006; Randles, 2013; Urness et al., 2016). Raof et al. (2019a) conducted an oxidation study on trimethylolpropane tricaprylate/tricaprate (TMPE $\mathrm{C} 8 / \mathrm{C} 10)$, trimethylolpropane trilaurate (TMPE C12), and trimethylolpropane trioleate (TMPE C18) in the presence of copper/steel catalyst. The ED$\mathrm{XRF}$ analysis revealed a highly dissolved copper concentration (>700 ppm) in the TMPE C8/C10 and TMPE C12 base oils compared with TMPE C18 $(<10 \mathrm{ppm})$. In the presence of metal surfaces, the presence of water and contaminants caused by incomplete esterification/transesterification of the starting polyol also contributes to catalytic decomposition. Randles (2013) mentioned the suitability of using phosphate additive to passivate the iron surfaces. The studies on the catalytic decomposition of TMPE on metal surfaces are still lacking and further works need to be done to help us establish a greater degree of understanding on this matter.

Malaysia, the world's second largest palm oil producer after Indonesia, contributes nearly half of global palm oil production each year. Although less than $10 \%$ of palm oil is used in the biodiesel and biolubricant streams (Salih and Salimon, 2021), it may eventually arouse concerns about food chain supply. Based on their oil content, both edible oils such as palm, olive, soy, con, and so on, as well as nonedible oils such as Jatropha, karanja, castor, and neem have high potential as neat oil (Singh et al., 2017; Jimenez-Lopez et al., 2020; Salih and Salimon, 2021). According to Salih and Salimon (2021) advanced separation techniques can also extract nonedible constituents from oil to make it food grade. Exploration of nonedible oil as a raw material to produce polyol ester could lead to the production of a stable food grade biolubricant (Gunam Resul et al., 2012; Gul et al., 2020). For example, $\mathrm{Ng}$ et al. (2022) evaluated an $80 \%$ yield of NPG ester from palm fatty acid distillate (PFAD) for the use in a two-stroke engine. In a different study, Cheryl-Low et al. (2021) reported $100 \%$ purity of polyol ester synthesized from lignocellulosic biomass. Also, to avoid competing with food value chain, many companies and private sectors are now seeking into reprocessing or re-refining technologies for used vegetable cooking oils. The idea is to recycle this feedstock into useable base oils for use in lubricant formulations, therefore adding value to the core business. This would allow major food companies to cover all disposal expenses and, in the long run, produce a "green" revenue stream for the company. The challenge is to find new and innovative technologies that can fully integrate the refining and pretreatment of used cooking oil into base oils that can be used as a feedstock in the TMPE production. The presence of heavy impurities and solid particles and also inconsistent quality of used vegetable cooking oils present other challenges in realizing this idea.

One common issue in developing a food grade lubricant is that some additives are not approved for use in food (Sherman and Totten, 2018). Globally, regulations limiting the contents of hazardous additives such as sulfated ash, phosphorus, and sulfur have been implemented (Azman et al., 2016; Rashmi et al., 2017). These bearing additives could reversely affect the performance of devices, in particular diesel engines (Rashmi et al., 2017). Centers (1992) reported that a neurotoxin substance from lubricant decomposition may be produced at extreme temperature $\left(350-700^{\circ} \mathrm{C}\right)$. For turbine engine oil application that used synthetic oil, when trimethylolpropane and phosphorus from the additive combines during thermal combustion, trimethylolpropane phosphate was formed. In addition, the decomposition of TMPE produced carboxylic acid (Kalman et al., 1985). Phosphorus was presented in antiwear additives, such as tricresyl phosphate (TCP, which is from tritolyl phosphate isomers) (Centers, 1992).

Sherman and Totten (2018) discovered differences between food grade and non-food grade water glycol hydraulic fluids. Because amine additives, which are essential for corrosion inhibitors, are prohibited for contact with food, approved additives with lower performance were used instead. Furthermore, food-grade hydraulic fluids frequently fail to meet ISO VG 46 specification (Sherman and Totten, 2018). According to Canter (2020), two commonly used antioxidants such as diphenyl amine and hindered phenolic derivatives could cause aquatic toxicity. When propylene glycol was used instead of diethylene glycol, which has superior lubricity properties, the results showed higher wear scar diameters as well as changes in oil density, pH, and pour point. Furthermore, product recalls would occur when food products were contaminated by non-food grade lubricant, gear oil, or grease, which could cause off-odor, offflavor, irritation, and intestinal discomfort (Gebarin, 2009). Because of its improved viscosity index and ability to withstand high temperatures, research into food grade additives in polyol ester, in particular, TMPE could be expanded. If modified with appropriate additives, TMPE has greater potential. Toxicity test is a method of confirming the claim of food grade, thereby assuring consumers and industry for the alternatives of mineral-based lubricant.

Other challenges related to the development of TMPE as food grade lubricants are the selection of catalyst during base oil synthesis. The impurities generated from the use of acidic catalyst during the incomplete esterification process (such as unreacted raw materials) or catalyst residue could contaminate the produced lubricant (Papadaki et al., 2018). Nowicki et al. (2019) acknowledged that homogeneous acid catalyst had disadvantages for instance, high corrosivity and difficult product recovery. As a result, a similar catalyst used in the food sector, Tin (II) bis(2-ethylhexanoate), which is neutral 
and noncorrosive, was selected for the investigation. The produced TMPE exhibited the smallest WSD $(0.64 \mathrm{~mm})$, the greatest anti-seizure properties $(3450 \mathrm{~N})$, and outstanding thermal stability at $400^{\circ} \mathrm{C}$, according to studies on high TMP dimers. The most crucial aspect was that proper catalyst selection enables the manufacturing of high-quality products without the requirement for high vacuum distillation operations (Nowicki et al., 2019). Papadaki et al. (2018) investigated the production of TMPE from a two-step bioprocess microbial oil and TMP. The esterification process used lipase enzyme, which yielded $83 \%$ of TMPE after $72 \mathrm{~h}$. However, of the TMPE's physicochemical properties were not disclosed. Therefore, it is recommended that the future research in TMPE production could opt for more environmentally friendly catalyst and green synthesis.

For engine oil application, the load-bearing capacity of pure bio lubricants was limited and eventually failed when subjected to higher loads (Kotturu et al., 2020). Most lubricants' performance reports focused on various speed and load conditions at short durations of testing, but there were few reports on long-term and continuous endurance testing under extreme load and speed conditions. Furthermore, the improvements in the engine and emission performance for alternative bio lubricants could have been investigated. Less study on the oxidative, thermal, and hydrolytic stability test is conducted on TMPE in engine oil application. The synergistic and adverse effect studies in particular additives could benefit the industry and engineers in the future.

Despite the many advantages of using TMPE, its usage as insulating fluids is often linked to several challenges too. Regardless of the fluid used to produce a transformer's insulation system, network operators confront challenges related to the system's moisture after many years of operation (Cybulski and Przybylek, 2021). Unfortunately, throughout the transformer's long-term operation, which can last up to 50 years, the water content in its insulating system gradually rises. If the moisture level is too high, the transformer can fail electrically. To reduce the risk of transformer failure, it is important to maintain the insulation moisture level low throughout the transformer's lifetime. A study by Cybulski and Przybylek (2021) shows a possibility of using $3 \mathrm{~A}$ molecular for continuous drying of ester during transformer operation. It is estimated that for a freebreathing transformer filled with mineral oil, $200 \mathrm{~kg}$ of molecular sieve should be suffice for 10 years of continuous drying. Natural ester and synthetic ester like TMPE would require lesser volume than mineral oil due to its high moisture absorbance capacity.

Hydraulic fluids in particular are very prone to water contamination during service, especially when esters are being used (Rowland et al., 2017). Some base stocks interact with water or metals to create by-products such as sludge and make hydraulic fluids inefficient. Deciding on the most lucrative hydraulic fluid for companies is very challenging because many factors need to be taken into consideration. The turbine oil stability test (TOST) has been widely used to assess the oxidative stability of hydraulic fluids. The test run at $95^{\circ} \mathrm{C}$, in the presence of water, metal catalyst, and air. The "dry" TOST method that operates at higher temperature $\left(120^{\circ} \mathrm{C}\right)$ and in the absence of water has been developed later on and has found to be less discriminatory on vegetable oil and esterbased hydraulic fluids (Petlyuk and Adams, 2004; Rowland et al., 2017). It is also critical that the test distinguishes between thermal degradation, oxidative degradation, and volatility. Some oven-aging or thermogravimetric analysis has resulted in incorrect results since the loss in sample weight and increase in viscosity might be ascribed to volatilization of the lighter components rather than chemical degradation (Rudnick, 2013). More appropriate bench tests are needed to simulate real-time operating conditions for hydraulic fluid application.

Plant oil-based MWF has limitations in oxidation stability, hydrolytic stability, and heat-bearing capacity due to their chemical structure, especially for its polyunsaturated fatty acid profiles, while MWF strongly favors for lubricant that contains highly saturated fatty acids (Wickramasinghe et al., 2020). However, the most successful formulation method for plant oil-based water-soluble MWFs is emulsification, in which the aquatic and oleic phases are mixed together and strongly shaken to disperse the oil droplets in water and vice versa (Coker, 2007). For an industrial heat treatment, palm oil has shown as an effective bio-quench ant for industrial heat treatment, in addition to its highest thermal stability as compared with sunflower, coconut, and mineral oil-based MWFs (Chandrakar et al., 2014). It is expected that palm oil-based TMPE has better opportunity in MWF application due to its enhanced hydrolytic stability and oxidation stability than the original palm oil.

Plant oil-based TMPE with three-branched chains of ester groups has provided an excellent friction reduction and antiwear performance although PEE was reported as the best candidate to the synthetic drilling mud formulation (Kania et al., 2018). As a recent off-shore regulations requirement, an enhancement of the synthetic drilling mud lubricity becomes crucial. Moreover, an addition of plant-based TMPE into the synthetic drilling mud also showed a lower force to initiate a fluid movement, for its shear-thinning rheology, instead of other improvements in drilling mud filtration properties. However, as mentioned in Section 3.7, TMPE as a biolubricant additive is not suitable for drilling mud with high solid content, which limits the application of TMPE only in low to medium solid-contents of drilling muds.

The question arises of how to convince industrial users to pay two-fold of the cost of mineral oil-based lubricants as the end products, no matter the excellent exhibited performance of formulated plant-oil-based lubricants. One can justify it from the standpoint of performance, warranty costs, avoiding early failure of the part, etc. despite evidence that costs can be cut by switching to synthetic lubricants. Their needs are so simple and petroleum oils and greases are so cheap that synthetics cannot compete for these applications, despite a widespread impression among industrial users that in general, synthetic lubricants protect well, last longer, and outperform their conventional counterparts. Thus, the conventional lubricants are currently still strongly entrenched.

The cost of producing biolubricant is not currently well established compared to the cost of biodiesel processing. Up to 
this point, biolubricant manufacturing has been scaled up to the pilot plant stage. Lubricant raw material costs are as essential as utility costs in determining annual operating cost of lubricant production (Kumar et al., 2020). The cost of raw material from neat resources to produce lubricant is approximately 2-4 times that of mineral and waste plant-based raw materials. As a result, the price of lubricant for bio-based oil is 2-3 times higher (Soufi et al., 2019). Moreover, bio-based and waste plant-based lubricants have lower carbon footprints than mineral oil lubricant. Thus, it is inferred that the waste management cost for mineral-based lubricant to reduce greenhouse gas emissions is higher.

\section{CONCLUSION}

The following conclusions can be drawn from the present review:

1. This review helps the readers to survey the potential formulation of TMPE with other base oils or additives. Since various functions of lubrication conditions are required in different lubricant applications, a scientific point of view of TMPE is also needed in terms of lubricant technology.

2. To date, research studies of lubricants formulation of plant oilbased TMPE are still vastly undergoing since TMPE has won the researchers' interest in the formulation of biolubricant for its enhancement of lubricant performance, qualities, and thermo-oxidative properties of biolubricant base oil.

\section{REFERENCES}

Abdul Sani, A. S., Rahim, E. A., Sharif, S., Sasahara, H., and Sasahara, H. (2019). Machining Performance of Vegetable Oil with Phosphonium- and Ammonium-Based Ionic Liquids via MQL Technique. J. Clean. Prod. 209, 947-964. doi:10.1016/j.jclepro.2018.10.317

Afifah, A. N., Syahrullail, S., Wan Azlee, N. I., and Rohah, A. M. (2021). Synthesis and Tribological Studies of Epoxidized Palm Stearin Methyl Ester as a Green Lubricant. J. Clean. Prod. 280, 124320-124329. doi:10.1016/j.jclepro.2020. 124320

Åkerman, C. O., Hagström, A. E. V. M., Mollaahmad, M. A., Karlsson, S., and Hatti-Kaul, R. (2011). Biolubricant Synthesis Using Immobilised Lipase: Process Optimisation of Trimethylolpropane Oleate Production. Process Biochem. 46 (12), 2225-2231. doi:10.1016/j.procbio.2011.08.006

Ali, I., Alharbi, O. M. L., Alothman, Z. A., Alwarthan, A., and Alwarthan, A. (2018). Facile and Eco-Friendly Synthesis of Functionalized Iron Nanoparticles for Cyanazine Removal in Water. Colloids Surf. B: Biointerfaces 171, 606-613. doi:10.1016/j.colsurfb.2018.07.071

Ali, I., Basheer, A. A., Kucherova, A., Memetov, N., Pasko, T., Ovchinnikov, K., et al. (2019). Advances in Carbon Nanomaterials as Lubricants Modifiers. J. Mol. Liquids, 279. Elsevier B.V, 251-266. doi:10.1016/j.molliq.2019.01.113

Alias, N. H., Yunus, R., and Idris, A. (2011). "Effect of Additives on Lubrication Properties of Palm Oil-Based Trimethylolpropane Ester for Hydraulic Fluid Application," in 3rd ISESEE 2011 - International Symposium and Exhibition in Sustainable Energy and Environment, 88-93. doi:10.1109/ISESEE.2011. 5977116

Alias, N. H., Yunus, R., Idris, A., and Omar, R. (2009). Effects of Additives on Oxidation Characteristics of palm Oil-based Trimethylolpropane Ester in Hydraulics Applications. Eur. J. Lipid Sci. Technol. 111, 368-375. doi:10. 1002/ejlt.200800136
3. TMPE was mostly studied as a biolubricant base oil in most potential applications such as engine oil, insulating fluid, heat transfer fluid, metal-working fluid, etc. except for the synthetic drilling mud application, where it is utilized as a lubricant additive.

4. The formulations of TMPE in numerous studies have considered the working functions to enhance tribology, rheology, as well as to maintain the condition of the lubricants itself.

5. The implementation of renewable resources in the production of lubricants could potentially reduce the carbon emissions associated with the process, packaging, and distribution, and eventually their whole life cycle. This effort is in line with the United Nation's target that is to achieve a truly global coalition for carbon neutrality by 2050 . The present study can support and encourage research on using plant-based TMPE as biolubricants.

\section{AUTHOR CONTRIBUTIONS}

$\mathrm{NR}, \mathrm{HH}, \mathrm{NM}$, and RY contributed to conception and design of the overall review. NR involved in planning, supervised and directed the work. $\mathrm{HH}$ and NM designed the figures and tables. NR, HH, and NM wrote the first draft and all sections of the manuscript. All authors discussed the results and commented on the manuscript. All authors contributed to manuscript revision, read, and approved the submitted version.

Almasi, S., Ghobadian, B., Najafi, G., and Soufi, M. D. (2021). A Review on BioLubricant Production from Non-edible Oil-Bearing Biomass Resources in Iran: Recent Progress and Perspectives. J. Clean. Prod. 290, 125830. doi:10.1016/j. jclepro.2021.125830

Aranzabe, E., Marcaide, A., Hernaiz, M., and Urang, N. (2011). Lengthening Biolubricants' Lifetime by Using Porous Materials. Environ. Manage. Pract., 371-386. doi:10.5772/22302

Arumugam, S., Sriram, G., and Ellappan, R. (2014). Bio-Lubricant-Biodiesel Combination of Rapeseed Oil: An Experimental Investigation on Engine Oil Tribology, Performance, and Emissions of Variable Compression Engine. Energy 72, 618-627. doi:10.1016/j.energy.2014.05.087

Attia, N. K., El-Mekkawi, S. A., Elardy, O. A., and Abdelkader, E. A. (2020). Chemical and Rheological Assessment of Produced Biolubricants from Different Vegetable Oils. Fuel 271, 117578. doi:10.1016/j.fuel.2020.117578

Aziz, N. A. M., Yunus, R., Rashid, U., and Syam, A. M. (2014). Application of Response Surface Methodology (RSM) for Optimizing the Palm-Based Pentaerythritol Ester Synthesis. Ind. Crops Prod. 62, 305-312. doi:10.1016/j. indcrop.2014.08.040

Aziz, N. A. M., Yunus, R., Rashid, U., and Zulkifli, N. W. M. (2016). Temperature Effect on Tribological Properties of Polyol Ester-Based Environmentally Adapted Lubricant. Tribology Int. 93, 43-49. doi:10. 1016/j.triboint.2015.09.014

Aziz, Nur., and Atiqah, M. (2015). Development of Food Grade Green Lubricant from Palm Oil Methyl Ester.

Azman, S. S. N., Zulkifli, N. W. M., Masjuki, H., Gulzar, M., and Zahid, R. (2016). Study of Tribological Properties of Lubricating Oil Blend Added with Graphene Nanoplatelets. J. Mater. Res. 31 (13), 1932-1938. doi:10.1557/jmr.2016.24

Bahadi, M., Salimon, J., and Derawi, D. (2021). Synthesis of Di-trimethylolpropane Tetraester-Based Biolubricant from Elaeis Guineensis Kernel Oil via Homogeneous Acid-Catalyzed Transesterification. Renew. Energ. 171, 981-993. doi:10.1016/j.renene.2021.02.163 
Bahadi, M., Yusoff, M. F. J. S., Salimon, J., and Derawi, D. (2019). Optimization of Response Surface Methodology by D-Optimal Design for Synthesis of FoodGrade Palm Kernel Based Biolubricant. Ind. Crops Prod. 139, 111452. doi:10. 1016/j.indcrop.2019.06.015

Bashiri, S., Ghobadian, B., Dehghani Soufi, M., and Gorjian, S. (2021). Chemical Modification of Sunflower Waste Cooking Oil for Biolubricant Production through Epoxidation Reaction. Mater. Sci. Energ. Tech. 4, 119-127. doi:10.1016/ j.mset.2021.03.001

Benedicto, E., Carou, D., and Rubio, E. M. 2017. Technical, Economic and Environmental Review of the Lubrication/Cooling Systems Used in Machining Processes. Proced. Eng. 184, 99-116. doi:10.1016/j.proeng.2017. 04.075

Bhaumik, S., Paleu, V., Pathak, R., Maggirwar, R., Katiyar, J. K., and Sharma, A. K. (2019). Tribological Investigation of R-GO Additived Biodegradable Cashew Nut Shells Liquid as an Alternative Industry Lubricant. Tribology Int. 135, 500-509. doi:10.1016/j.triboint.2019.03.007

Bolina, I. C. A., Gomes, R. A. B., and Mendes, A. A. (2021). Biolubricant Production from Several Oleaginous Feedstocks Using Lipases as Catalysts: Current Scenario and Future Perspectives. Bioenerg. Res. 14 (4), 1039-1057. doi:10.1007/s12155-020-10242-4

Brinksmeier, E., Meyer, D., Huesmann-Cordes, A. G., and Herrmann, C. 2015. Metalworking Fluids-Mechanisms and Performance. CIRP Ann. 64 (2): 605-628. doi:10.1016/j.cirp.2015.05.003

Camargo, R. P. L., Carrim, A. J. I., and Antoniosi Filho, N. R. (2017). Study Ecotoxicity of Biodiesel from Residual Oils and Fats and the Effects of Salinity Aquatic Ecosystems. Eec 12 (1), 63-67. doi:10.5132/eec.2017.01.08

Canter, N. (2020). Biodegradable Lubricants: Working Definitions, Review of Key Applications and Prospects for Growth. Tribology \& Lubrication Technology. December 2020.

Capuzzi, L., Digioia, F., and Sagliano, A. (2019). Low Pour Point Trimethylolpropane Ester. EP 3307857 B1, issued 2019.

Cecilia, J. A., Ballesteros Plata, D., Alves Saboya, R. M., Tavares de Luna, F. M., Cavalcante, C. L., and Rodríguez-Castellón, E. (2020). An Overview of the Biolubricant Production Process: Challenges and Future Perspectives. Processes 8, 257. doi:10.3390/pr8030257

Centers, P. W. (1992). Potential Neurotoxin Formation in Thermally Degraded Synthetic Ester Turbine Lubricants, 66. doi:10.1007/bf01981509

Chan, C.-H., Tang, S. W., Mohd, N. K., Lim, W. H., Yeong, S. K., and Idris, Z. (2018). Tribological Behavior of Biolubricant Base Stocks and Additives. Renew. Sustain. Energ. Rev. 93, 145-157. doi:10.1016/j.rser.2018.05.024

ChandrakarKumar, J., and Amit, S. (2014). The Prospects of Vegetable Based Oils as Metal Working Fluids in Manufacturing Application -A Review. Int. J. Eng. Res. Tech. 3 (5), 2196-2203.

Chang, T.-S., Yunus, R., Rashid, U., Choong, T. S. Y., Awang Biak, D. R., and Syam, A. M. (2015). Palm Oil Derived Trimethylolpropane Triesters Synthetic Lubricants and Usage in Industrial Metalworking Fluid. J. Oleo Sci. 64 (2), 143-151. doi:10.5650/jos.ess 14162

Cheryl-Low, Y. L., Kong, P. S., and Lee, H. V. (2021). Environmentally Adapted Bio-Oil Compounds-Derived Polyolesters Synthesis: Optimization and Properties of Base Fluids. J. Hazard. Mater. 407, 124365. doi:10.1016/j. jhazmat.2020.124365

Ciba (2003). Ciba ${ }^{\circledR}$ IRGANOX ${ }^{\circledR}$ L 57 Aminic Antioxidant. Datasheet June.

Claeys, S. G., Lievens, S. S., Paul Van De VenZhou, Z., Miller, S. J., Schexnaydre, R. J., et al. (2012). Ester Based Heat Transfer Fluid Useful as Coolant for Electric Vehicles. US 2012/0164506 A1, issued 2012.

Coker, A. K. (2007). Physical Properties of Liquids and Gases. Ludwig's Appl. Process Des. Chem. Petrochemical Plants, 103-132. doi:10.1016/b978075067766-0/50010-5

Corbett, P. M., Ryan, H. T., and Sheets, R. M. (2008). Food Grade Lubricant Compositions. United States Patent Application Publication. issued 2008.

Cybulski, M., and Przybylek, P. (2021). Application of Molecular Sieves for Drying Transformers Insulated with Mineral Oil, Natural Ester, or Synthetic Ester. Energies 14 (6), 1719-1813. doi:10.3390/en14061719

Dandan, M. A., Samion, S., and Musa, M. N. (2018). A Comprehensive Review on Palm Oil and the Challenges Using Vegetable Oil as Lubricant Base-Stock. J. Adv. Res. Fluid Mech. Therm. Sci. 52 (2).

Data Bridge Market Research. 2021. Global Drilling Fluid Additives Market Industry Trends and Forecast to 2028." Data Bridge Market Research. Available at: https://www.databridgemarketresearch.com/reports/global-drilling-fluidadditives-market\#.

Dehghani Soufi, M., Ghobadian, B., Mousavi, S. M., Najafi, G., and Aubin, J. (2019). Valorization of Waste Cooking Oil Based Biodiesel for Biolubricant Production in a Vertical Pulsed Column: Energy Efficient Process Approach. Energy 189, 116266-116312. doi:10.1016/j.energy.2019.116266

El-magly, I. A., Nagib, H. K., and Mokhtar, W. M. (2018). Cordial PhysicoChemical Characteristics of Some Trimethylolpropane Triesters as Base Synthetic Lubricant for Turbo- Jet Aircrafts. Egypt. J. Pet. 27 (4), 1123-1130. doi:10.1016/j.ejpe.2018.04.002

Fernandes, K. V., Papadaki, A., da Silva, J. A. C., Fernandez-Lafuente, R., Koutinas, A. A., and Freire, D. M. G. (2018). Enzymatic Esterification of Palm Fatty-Acid Distillate for the Production of Polyol Esters with Biolubricant Properties. Ind. Crops Prod. 116, 90-96. doi:10.1016/j.indcrop.2018.02.058

Fitch, J. C., Williamson, M., and Gebarin, S. (2009). Industrial Food-Grade Lubricants Guide. Clarion Lubricants.

Fofana, I. (2013). 50 Years in the Development of Insulating Liquids. IEEE Electr. Insul. Mag. 29 (5), 13-25. doi:10.1109/mei.2013.6585853

Fortune Business Insights (2020). "Metalworking Fluids Market Size," in Fortune Business Insights. 2020. https://www.fortunebusinessinsights.com/industryreports/metalworking-fluids-market-101391.

Frauscher, M., Besser, C., Allmaier, G., and Dörr, N. (2017). Oxidation Products of Ester-Based Oils with and without Antioxidants Identified by Stable Isotope Labelling and Mass Spectrometry. Appl. Sci. 7 (12), 396-418. doi:10.3390/ app7040396

Gebarin, S. (2009). The Basics of Food Grade Lubricants. "Machinery Lubrication.

Global Industry Analysts (2021). Biolubricants - Global Market Trajectory \& Analytics. Research and Markets. Available at: https://www.strategyr.com/ market-report-biolubricants-forecasts-global-industry-analysts-inc.asp (Aceesed November 5, 2021).

Grand View Research (2020). Drilling Fluids Market Size, Share \& Trends Analysis Report by Product (Oil-Based, Synthetic-Based, Water-Based), by Application (Onshore, Offshore), by Region, and Segment Forecasts, 2020 - 2027. Grand View Research. Available at: https://www.grandviewresearch.com/industryanalysis/drilling-fluids-market-analysis.

Gul, M., Zulkifli, N. W. M., Masjuki, H. H., Kalam, M. A., Mujtaba, M. A., Harith, M. H., et al. (2020). Effect of TMP-Based-Cottonseed Oil-Biolubricant Blends on Tribological Behavior of Cylinder Liner-Piston Ring Combinations. Fuel 278, 118242-118310. doi:10.1016/j.fuel.2020.118242

Gulzar, M., Masjuki, H. H., Alabdulkarem, A., Kalam, M. A., Varman, M., Zulkifli, N. W. M., et al. (2017). Chemically Active Oil Filter to Develop Detergent Free Bio-Based Lubrication for Diesel Engine. Energy 124, 413-422. doi:10.1016/j. energy.2017.02.072

Gunam Resul, M. F. M., Mohd. Ghazi, T. I., and Idris, A. (2012). Kinetic Study of Jatropha Biolubricant from Transesterification of Jatropha Curcas Oil with Trimethylolpropane: Effects of Temperature. Ind. Crops Prod. 38 (1), 87-92. doi:10.1016/j.indcrop.2012.01.012

Gunawidjaja, R., Nawani, P., and Eilers, H. (2019). High Performance Environmentally Acceptable Hydraulic Fluid. US 10190067B2. issued 2019.

Hamdan, S. H., Chong, W. W. F., Ng, J.-H., Chong, C. T., and Zhang, H. (2018). Nano-Tribological Characterisation of Palm Oil-Based Trimethylolpropane Ester for Application as Boundary Lubricant. Tribology Int. 127, 1-9. doi:10. 1016/j.triboint.2018.05.036

Hamid, H. A., Yunus, R., Rashid, U., Choong, T. S. Y., Ali, S., and Syam, A. M. (2016). Synthesis of High Oleic Palm Oil-Based Trimethylolpropane Esters in a Vacuum Operated Pulsed Loop Reactor. Fuel 166, 560-566. doi:10.1016/j.fuel. 2015.11.022

Ho, C. K., McAuley, K. B., and Peppley, B. A. (2019). Biolubricants through Renewable Hydrocarbons: A Perspective for New Opportunities. Renew. Sustain. Energ. Rev. 113, 109261-109317. doi:10.1016/j.rser.2019.109261

Hof, Matthias., Baehr, Horst., Moucha, Marc., Cooban, Nigel., and Willing, Andreas. (2008i2008). Polyol Esters for Transformers. US 2008/0033201 A1. U S Patent and Trademark Office. US Patent 2008/0033201 A1.

Hoong, S. S., Arniza, M. Z., Mariam, N. M. D. N. S., Armylisas, A. H. N., and Yeong, S. K. (2019). Synthesis and Physicochemical Properties of Novel Lauric Acid Capped Estolide Esters and Amides Made from Oleic Acid and Their Evaluations for Biolubricant Basestock. Ind. Crops Prod. 140, 111653-111711. doi:10.1016/j.indcrop.2019.111653 
Hossain, M. A., Mohamed Iqbal, M. A., Julkapli, N. M., San Kong, P., Ching, J. J., and Lee, H. V. (2018). Development of Catalyst Complexes for Upgrading Biomass into Ester-Based Biolubricants for Automotive Applications: A Review. RSC Adv. 8 (10), 5559-5577. doi:10.1039/c7ra11824d

Igartua, A., Mendoza, G., Fernandez-Diaz, B., Urquiola, F., Vivanco, S., and Arguizoniz, R. (2011). Vegetable Oils as Hydraulic Fluids for Agricultural Applications. Grasas y Aceites 62 (1), 29-38. doi:10.3989/gya.056210

Jason, Y. J. J., How, H. G., Teoh, Y. H., and Chuah, H. G. (2020). A Study on the Tribological Performance of Nanolubricants. Processes 8 (11), 1372-1433. doi:10.3390/pr8111372

Jimenez-Lopez, C., Carpena, M., Lourenço-Lopes, C., Gallardo-Gomez, M., Lorenzo, J. M., Barba, F. J., et al. (2020). Bioactive Compounds and Quality of Extra Virgin Olive Oil. Foods 9 (8), 1014-1031. doi:10.3390/foods9081014

Kalman, D. A., Voorhees, K. J., Osborne, D., and Einhorn, I. N. (1985). Production of a Bicyclophosphate Neurotoxic Agent during Pyrolysis of Synthetic Lubricant Oil. J. Fire Sci. 3 (5), 322-329. doi:10.1177/073490418500300503

Kamarudin, N. S., Veny, H., Sidek, N. F., Abnisa, F., Sazali, R. A., and Aziz, N. (2020). Investigation on Synthesis of Trimethylolpropane (TMP) Ester from Non-edible Oil. Bull. Chem. React. Eng. Catal. 15 (3), 808-817. doi:10.9767/ bcrec.15.3.8862.808-817

Kania, D., Yunus, R., Omar, R., Abdul Rashid, S., Mohamed Jan, B., and Arsanjani, N. 2018. "Nonionic Polyol Esters as Thinner and Lubricity Enhancer for Synthetic-Based Drilling Fluids." J. Mol. Liquids 266: 846-855. doi:10.1016/j. molliq.2018.07.014

Kania, D., Yunus, R., Omar, R., Abdul Rashid, S., Mohamed Jan, B., and Aulia, A. (2021). Adsorption of Non-ionic Surfactants on Organoclays in Drilling Fluid Investigated by Molecular Descriptors and Monte Carlo Random Walk Simulations. Appl. Surf. Sci. 538, 148154-148159. doi:10.1016/j.apsusc.2020. 148154

Kanoh, T., Iwabuchi, H., Hoshida, Y., Yamada, J., Hikosaka, T., Yamazaki, A., et al. (2008). "Analyses of Electro-Chemical Characteristics of Palm Fatty Acid Esters as Insulating Oil," in 2008 IEEE International Conference on Dielectric Liquids (IEEE), 1-4. doi:10.1109/icdl.2008.4622456

Kanoh, T., Yamada, J. I., Koide, H., and Hatta, Y. (2012). Base Agent for Electrical Insulating Oil. US Patent 8, 187508.

Kathamore, P. S., and Bachchhav, B. D. (2021). Tribological Investigations of Trimethylolpropane Trioleate Bio-Based Lubricants. Ilt 73 (7), 1074-1083. doi:10.1108/ILT-05-2021-0157

Kauffman, R. E. (2006). Mechanism for Reaction between Polyolester Lubricant and Ferrous Metals, Part II: Research Phase." in. ASHRAE Trans. 112 (PART 1), 762-770.

Kim, H., Choi, N., Kim, Y., Kim, H. R., Lee, J., and Kim, I. H. (2019). Immobilized Lipase-Catalyzed Esterification for Synthesis of Trimethylolpropane Triester as a Biolubricant. Renew. Energ. 130 (C), 489-494. doi:10.1016/j.renene.2018. 06.092

Kotia, A., Chowdary, K., Srivastava, I., Ghosh, S. K., and Ali, M. K. A. (2020). Carbon Nanomaterials as Friction Modifiers in Automotive Engines: Recent Progress and Perspectives. J. Mol. Liquids 310, 113200-113213. doi:10.1016/j. molliq.2020.113200

Kotturu, C. M. V., Srinivas, V., Vandana, V., Chebattina, K. R. R., and Seetha Rama Rao, Y. (2020). Investigation of Tribological Properties and Engine Performance of Polyol Ester-Based Bio-Lubricant: Commercial Motorbike Engine Oil Blends. Proc. Inst. Mech. Eng. D: J. Automobile Eng. 234 (5), 1304-1317. doi:10.1177/0954407019878359

Krevalis, M. A., Jr., Schlosberg, R. H., and Duncan, C. B. (1996). Refrigeration Working Fluid Compositions Containing Difluoroethane or Pentafluoroethane and a Polyolester Lubricant. US5494597A, issued 1996.

Kumar, L. R., YellapuYellapu, S. K. R. D. T., Tyagi, R. D., and Drogui, P. (2020). Cost, Energy and GHG Emission Assessment for Microbial Biodiesel Production through Valorization of Municipal Sludge and Crude Glycerol. Bioresour. Tech. 297, 122404-122412. doi:10.1016/j.biortech.2019.122404

Lawal, S. A., Choudhury, I. A., and Nukman, Y. 2012. Application of Vegetable OilBased Metalworking Fluids in Machining Ferrous Metals-A Review. Int. J. Machine Tools Manufacture 52 (1): 1-12. doi:10.1016/j.ijmachtools.2011. 09.003

Li, K., Aghazadeh, F., Hatipkarasulu, S., and Ray, T. G. (2003). Health Risks from Exposure to Metal-Working Fluids in Machining and Grinding Operations. Int. J. Occup. Saf. Ergon. 9 (1), 75-95. doi:10.1080/10803548.2003.11076555
Liñeira del Río, J. M., Guimarey, M. J. G., Comuñas, M. J. P., López, E. R., Amigo, A., and Fernández, J. (2018). Thermophysical and Tribological Properties of Dispersions Based on Graphene and a Trimethylolpropane Trioleate Oil. J. Mol. Liquids 268, 854-866. doi:10.1016/j.molliq.2018.07.107

LubesNGreases.com (2021). Malaysia Promotes Biolubricants. LubesNGreases. Available at: https://www.lubesngreases.com/lubereport-asia/1_53/malaysiapromotes-biolubricants/(Accessed November 15, 2021).

Luckham, P. F., and Rossi, S. 1999. The Colloidal and Rheological Properties of Bentonite Suspensions. Adv. Colloid Interf. Sci. 82 (1): 43-92. doi:10.1016/ S0001-8686(99)00005-6

Mahmud, H. A., Salih, N., and Salimon, J. (2015). Oleic Acid Based Polyesters of Trimethylolpropane and Pentaerythritol for Biolubricant Application. Malaysian J. Anal. Sci. 19 (1), 97-105.

MarketsandMarkets (2021). Transformer Oil Market. Available at: https://www. marketsandmarkets.com/Market-Reports/transformer-oil-market-967.html.

Masripan, N. A., Azli Salim, M., Omar, G., AdzniSaad, M., Abdul Hamid, N., Imran Syakir, M., et al. (2020). Vegetable Oil as Bio-Lubricant and Natural Additive in Lubrication: A Review. Int. J. Nanoelectronics Mater. 13 (Special Issue ISSTE2019), 161-176.

Mathiesen, T. (1998). Modified TMP Esters as Multifunctional Additives in Metalworking Fluids. J. Synth. Lubr. 14 (4), 381-390. doi:10.1002/jsl. 3000140405

McShane, C. P., Gauger, G. A., and Luksich, J. (1999). "Fire Resistant Natural Ester Dielectric Fluid and Novel Insulation System for its Use," in 1999 IEEE/IPES Transmission \&Distribution Conference, New Orleans, LA, 1-5. doi:10.1109/ tdc. 1999.756167

Minami, I. (2017). Molecular Science of Lubricant Additives. Appl. Sci. 7 (5), 445-533. doi:10.3390/app7050445

Mobarak, H. M., Niza Mohamad, E., Masjuki, H. H., Kalam, M. A., al Mahmud, K. A. H., Habibullah, M., et al. (2014). The Prospects of Biolubricants as Alternatives in Automotive Applications. Renew. Sustain. Energ. Rev. 33, 34-43. doi:10.1016/j.rser.2014.01.062

Moreira, D. R., Chaves, P. O. B., Ferreira, E. N., Arruda, T. B. M. G., Rodrigues, F. E. A., Neto, J. F. C., et al. (2020). Moringa Polyesters as Eco-Friendly Lubricants and its Blends with Naphthalenic Lubricant. Ind. Crops Prod. 158, 112937-112939. doi:10.1016/j.indcrop.2020.112937

Nair, S. S., Nair, K. P., and Rajendrakumar, P. K. (2017). Evaluation of Physicochemical, Thermal and Tribological Properties of Sesame Oil (Sesamum Indicum L.): A Potential Agricultural Crop Base Stock for EcoFriendly Industrial Lubricants. Ijarge 13 (1), 77-90. doi:10.1504/IJARGE.2017. 084037

Napper, D. H. 1977. Steric Stabilization. J. Colloid Interf. Sci. 58 (2). 390-407. doi:10.1016/0021-9797(77)90150-3

Negi, P., Singh, Y., and Tiwari, K. (2021). A Review on the Production and Characterization Methods of Bio-Based Lubricants. Mater. Today Proc. 46, 10503-10506. doi:10.1016/j.matpr.2020.12.1211

Ng, B. Y. S., Ong, H. C., LauLau, H. L. N., Ishak, N. S., Elfasakhany, A., and Lee, H. V. (2022). Production of Sustainable Two-Stroke Engine Biolubricant Ester Base Oil from Palm Fatty Acid Distillate. Ind. Crops Prod. 175 (January), 114224. doi:10.1016/j.indcrop.2021.114224

Nowicki, J., Drabik, J., Woszczyński, P., Gębura, K., Nowakowska-Bogdan, E., and Kozdrach, R. (2019). Tribological Characterisation of Plant Oil Derived Fatty Acid Esters of Higher Polyols: Comparative Experimental Study. Lubrication Sci. 31 (3), 61-72. doi:10.1002/1s.1448

Owuna, F. J., Dabai, M. U., Sokoto, M. A., Dangoggo, S. M., Bagudo, B. U., BirninYauri, U. A., et al. (2020). Chemical Modification of Vegetable Oils for the Production of Biolubricants Using Trimethylolpropane: A Review. Egypt. J. Pet. 29 (1), 75-82. doi:10.1016/j.ejpe.2019.11.004

Owuna, F. J. (2020). Stability of Vegetable Based Oils Used in the Formulation of Ecofriendly Lubricants - a Review. Egypt. J. Pet. 29 (3), 251-256. doi:10.1016/j. ejpe.2020.09.003

Papadaki, A., Fernandes, K. V., Chatzifragkou, A., Aguieiras, E. C. G., da Silva, J. A. C., Fernandez-Lafuente, R., et al. (2018). Bioprocess Development for Biolubricant Production Using Microbial Oil Derived via Fermentation from Confectionery Industry Wastes. Bioresour. Tech. 267, 311-318. doi:10. 1016/j.biortech.2018.07.016

Pathak, M. K., Joshi, A., Mer, K. K. S., Katiyar, J. K., and Patel, V. K. (2019). "Potential of Bio-Lubricants in Automotive Tribology," in Energy, 
Environment, and Sustainability. Editors J. Katiyar, S. Bhattacharya, V. Patel, and V. Kumar (Singapore: Springer). doi:10.1007/978-981-15-0434-1_11

Persistance Market Research (2017). Polyol Ester Market: Global Industry Analysis (2012-2016) and Forecast (2017-2027)." Polyol Ester Market To Expand At a Robust CAGR of 5.1\% by 2027 2026, 1-396.

Petlyuk, A. M., and Adams., R. J. (2004). Oxidation Stability and Tribological Behavior of Vegetable Oil Hydraulic Fluids. Tribology Trans. 47 (2), 182-187. doi:10.1080/05698190490431849

Poopal, R.-K., Zhang, J., Zhao, R., Ramesh, M., and Ren, Z. (2020). Biochemical and Behavior Effects Induced by Diheptyl Phthalate (DHpP) and Diisodecyl Phthalate (DIDP) Exposed to Zebrafish. Chemosphere 252, 126498-126512. doi:10.1016/j.chemosphere.2020.126498

Qazi, S. (2017). "Solar Thermal Electricity and Solar Insolation," in Standalone Photovoltaic (PV) Systems for Disaster Relief and Remote Areas (Elsevier Science), 203-237. doi:10.1016/b978-0-12-803022-6.00007-1

Qiao, S., Shi, Y., Wang, X., Lin, Z., and Jiang, Y. (2017). Synthesis of Biolubricant Trimethylolpropane Trioleate and its Lubricant Base Oil Properties. Energy Fuels 31 (7), 7185-7190. doi:10.1021/acs.energyfuels.7b00876

Qiu, W., and Brown, P. A. (2013). Dielectric Fluids Comprising Polyol Esters, 9028727 B2. US Patent.

Radhika, P., Sobhan, C. B., and Chakravorti, S. (2021). Improved Tribological Behavior of Lubricating Oil Dispersed with Hybrid Nanoparticles of Functionalized Carbon Spheres and Graphene Nano Platelets. Appl. Surf. Sci. 540, 148402-148412. doi:10.1016/j.apsusc.2020.148402

Rama Rao Chebattina, K., Srinivas, V., Pranay, G. V. S., Vishwanath Krishna, P., and Jagadhi, S. P. (2019). Tribological Characteristics of Calophyllum Ester Based Bio-Lubricant - Commercial Engine Oil Blends. IOP Conf. Ser. Mater. Sci. Eng. 653, 012013-012017. doi:10.1088/1757-899X/653/1/012013

Randles, S. J. (2013). "Esters," in Synthetics, Mineral Oils, and Bio-Based Lubricants: Chemistry and Technology. Editor L. R. Rudnick. Second Edi (CRC Press), 61-88.

Rao, T. V. V. L. N., Ahmad, M., Rani, A., Awang, M., Baharom, M., and Uemura, Y. (2018). An Overview of Research on Biolubricants in Malaysia and Japan for Tribological Applications. Jurnal Tribologi 18.

Raof, N. A., Rashid, U., Yunus, R., Azis, N., and Yaakub, Z. (2016). Development of Palm-Based Neopentyl Glycol Diester as Dielectric Fluid and its Thermal Aging Performance. IEEE Trans. Dielect. Electr. Insul. 23 (4), 2051-2058. doi:10.1109/ tdei.2016.7556478

Raof, N. A., Rashid, U., Yunus, R., Azis, N., and Yaakub, Z. 2019c. Effects of Molecular Structure on the Physical, Chemical, and Electrical Properties of Ester-Based Transformer Insulating Liquids. J. Am. Oil Chem. Soc. 96 (2019). 607-616. doi:10.1002/aocs.12212

Raof, N. A., Yunus, R., Rashid, U., Norhafiz Azisand Yaakub, Z. (2019a). Effect of Molecular Structure on Oxidative Degradation of Ester Based Transformer Oil. Tribology Int. 140 (December). doi:10.1016/j.triboint.2019.105852

Raof, N. A., Yunus, R., Rashid, U., Norhafiz Azisand Yaakub, Z. (2019b). Effects of Palm-Based Trimethylolpropane Ester/Mineral Oil Blending on Dielectric Properties and Oxidative Stability of Transformer Insulating Liquid. IEEE Trans. Dielect. Electr. Insul. 26 (6), 1771-1778. doi:10.1109/TDEI.2019.008128

Rapoport, L., Leshchinsky, V., Lvovsky, M., Nepomnyashchy, O., Volovik, Y., and Tenne, R. (2002). Mechanism of Friction of Fullerenes. Ind. Lubrication Tribology 54 (4), 171-176. doi:10.1108/00368790210431727

Rasep, Z., Muhammad Yazid, M. N. A. W., and Samion, S. (2021). Lubrication of Textured Journal Bearing by Using Vegetable Oil: A Review of Approaches, Challenges, and Opportunities. Renew. Sustain. Energ. Rev. 146, 111191-111214. doi:10.1016/j.rser.2021.111191

Rashmi, W., Khalid, M., Lim, X. Y., Gupta, T. C. S. M., and Arwin, G. Z. (2017). Tribological Studies on Graphene/TMP Based Nanolubricant. J. Eng. Sci. Tech. 12 (2), 365-373.

Reeves, C. J., Siddaiah, A., and Menezes, P. L. (2017). A Review on the Science and Technology of Natural and Synthetic Biolubricants. J. Bio Tribo Corros 3 (11), 1-27. doi:10.1007/s40735-016-0069-5

Rico, F. J. E., Battez, H. A., and Cuervo, G. D. (2002). Wear Prevention Characteristics of Binary Oil Mixtures. Wear 253 (7-8). doi:10.1016/S00431648(02)00229-6

Robiah, Y., Ooi, T. L. A. F., Iyuke, S. E., and Idris, A. (2003). Preparation and Characterization of Trimethylolpropane Esters from Palm Kernel Oil Methyl Esters. J. Oil Palm Res. 15 (2), 42-49.
Rochmat, A., Dudayev Alfaruqi, A., Saefuri, M., Suaedahand Nurtanto, M. (2020). Synthesis Biolubricant by Esterification of Castor Oil (Jatropha Curcas L-Oil) with Chlorate Acid Catalyst. J. Phys. Conf. Ser., 1573. IOP Publishing, 012004-012007. doi:10.1088/1742-6596/1573/1/012004

Rowland, R G., Dong, J., and Migdal, C. A. (2017). "Antioxidants," in Lubricant Additives: Chemistry and Applications. Editor Leslie. R. Rudnick. Third Edit (Taylor \& Francis), 3-103. doi:10.1201/9781315120621-1

Rozaki, N. Z., Gan, S.-N., and Ang, D. T.-C. (2017). Environmentally Friendly OilModified Polyesters as Polymeric Plasticizers for Poly(Vinyl Chloride) J. Polym. Environ. 25 (2), 286-295. doi:10.1007/s10924-016-0810-7

Rozga, P., Beroual, A., Przybylek, P., Jaroszewski, M., and Strzelecki, K. (2020). A Review on Synthetic Ester Liquids for Transformer Applications. Energies 13 (23), 6429-6433. doi:10.3390/en13236429

Rudnick, Leslie. R. (2013). in Synthetics, Mineral Oils, and Bio-Based Lubricants: Chemistry and Technology. Editor Leslie. R. Rudnick. Second (Boca Raton, Florida: CRC Press).

Rudnick, L. R. (2017). Lubricant Additives: Chemistry and Applications. Third EditionThird Edit. CRC Press.

Salaji, S., and Jayadas, N. (2021). Evaluation of Physicochemical and Tribological Properties of Chaulmoogra (Hydnocarpus Wightianus) Oil as Green Lubricant Base Stock. Proc. Inst. Mech. Eng. J: J. Eng. Tribology 235 (2), 376-385. doi:10. 1177/1350650119899529

Salih, N., and Salimon, J. (2021). A Review on New Trends, Challenges and Prospects of Ecofriendly Friendly Green Food-Grade Biolubricants. Biointerface Res. Appl. Chem. 12 (1), 1185-1207. doi:10.33263/briac121. 11851207

Salih, N., Salimon, J., Yousif, E., and Abdullah, B. M. (2013). Biolubricant Basestocks from Chemically Modified Plant Oils: Ricinoleic Acid BasedTetraesters. Chem. Cent. J. 7 (1), 1-13. doi:10.1186/1752-153X-7-128

Salimon, J., Nallathamby, N., Salih, N., and Abdullah, B. M. (20112011). Synthesis and Physical Properties of Estolide Ester Using Saturated Fatty Acid and Ricinoleic Acid. J. Automated Methods Manage. Chem. 2011, 1-4. doi:10. $1155 / 2011 / 263624$

Samidin, S., Salih, N., and Salimon, J. (2021). Synthesis and Characterization of Trimethylolpropane Based Esters as Green Biolubricant Basestock. Biointerface Res. Appl. Chem. 11 (5), 13638-13651. doi:10.33263/BRIAC115.1363813651

Sani, A., Sahab, A., Abd Rahim, E., Talib, N., Kamdani, K., and Rahim, M. (2017). Performance Evaluation of Palm-Olein TMP Ester Containing Hexagonal Boron Nitride and an Oil Miscible Ionic Liquid as Bio-Based Metalworking Fluids/Amiril Sahab Abdul Sani. [et Al.]. J. Mech. Eng. (Jmeche) 1, 223-234

Shafi, W. K., Raina, A., and Ul Haq, M. I. (2018). Friction and Wear Characteristics of Vegetable Oils Using Nanoparticles for Sustainable Lubrication. Tribology Mater. Surf. Inter. 12 (1), 27-43. doi:10.1080/17515831.2018.1435343

Shah, R., Woydt, M., and Wong, H. (2021). Alternative Base Oils: A Perspective. INFORM by AOCS.

Sharma, B. K., Perez, J. M., and Erhan, S. Z. (2007). Soybean Oil-Based Lubricants: A Search for Synergistic Antioxidants. Energy Fuels 21 (4), 2408-2414. doi:10. 1021/ef0605854

Sharma, U. C., and Sachan, S. (2019). Friction and Wear Behavior of Karanja Oil Derived Biolubricant Base Oil. SN Appl. Sci. 1 (7). doi:10.1007/s42452-0190706-y

Sherman, J. v., and Totten, G. E. (2018). Food-Grade Fire-Resistant Water Glycol Hydraulic Fluids. SAE Int., 1-12.

Singh, A., Chauhan, P., and Mamatha, T. G. (2020). A Review on Tribological Performance of Lubricants with Nanoparticles Additives. Mater. Today Proc 25, 586-591. Elsevier Ltd. doi:10.1016/j.matpr.2019.07.245

Singh, Y., Farooq, A., Raza, A., Mahmood, M. A., and Jain, S. (2017). Sustainability of a Non-edible Vegetable Oil Based Bio-Lubricant for Automotive Applications: A Review. Process Saf. Environ. Prot. 111, 701-713. doi:10. 1016/j.psep.2017.08.041

Singh, Y., Sharma, A., and Singla, A. (2019). Non-edible Vegetable Oil-Based Feedstocks Capable of Bio-Lubricant Production for Automotive Sector Applications-A Review. Environ. Sci. Pollut. Res. 26 (15), 14867-14882. doi:10.1007/s11356-019-05000-9

Srinivas, V., Chebattina, K. R. R., Pranay, G. V. S., Lakkoju, B., and Vandana, V. (2020). Tribological Properties of Polyol Ester - Commercial Motorbike Engine Oil Blends. Journal of King Saud University - Engineering Sciences, 1-10. 
Syahrullail, S., Kamitani, S., and Shakirin, A. (2013). Performance of Vegetable Oil as Lubricant in Extreme Pressure Condition. Proced. Eng. 68, 172-177. doi:10. 1016/j.proeng.2013.12.164

Talib, N., Amiril Sahab, A. S., and Nur Adlisham, H. (2019). Modified Jatropha NanoLubricant as Metalworking Fluid for Machining Process. Jurnal Tribologi 23, 90-96.

Talib, N., and Rahim, E. A. (2016). The Effect of Tribology Behavior on Machining Performances when Using Bio-Based Lubricant as a Sustainable Metalworking Fluid. Proced. CIRP 40, 504-508. doi:10.1016/j.procir.2016.01.116

Talib, N., and Rahim, E. A. (2014). The Performance of Modified Jatropha-Oil Based Trimethylolpropane (TMP) Ester on Tribology Characteristic for Sustainable Metalworking Fluids (MWFs). Amm 660, 357-361. Trans Tech Publ. doi:10.4028/www.scientific.net/amm.660.357

Troncoso, F. D., and Tonetto, G. M. (2022). Highly Stable Platinum Monolith Catalyst for the Hydrogenation of Vegetable Oil. Chem. Eng. Process. - Process Intensification 170, 108669. doi:10.1016/j.cep.2021.108669

Tulashie, S. K., and Kotoka, F. (2020). The Potential of Castor, Palm Kernel, and Coconut Oils as Biolubricant Base Oil via Chemical Modification and Formulation. Therm. Sci. Eng. Prog. 16, 100480-100486. doi:10.1016/j.tsep.2020.100480

Uosukainen, E., Linko, Y.-Y., Lämsä, M., Tervakangas, T., and Linko, P. (1998). Transesterification of Trimethylolpropane and Rapeseed Oil Methyl Ester to Environmentally Acceptable Lubricants. J. Amer Oil Chem. Soc. 75 (11), 1557-1563. doi:10.1007/s11746-998-0094-8

Urness, K. N., Gough, R. V., Widegren, J. A., and Bruno, T. J. (2016). Thermal Decomposition Kinetics of Polyol Ester Lubricants. Energy Fuels 30 (12), 10161-10170. doi:10.1021/acs.energyfuels.6b01863

van der Ven, L. T. M., Schoonen, W. G., Groot, R. M., den Ouden, F., Heusinkveld, H. J., Zwart, E. P., et al. (2020). The Effects of Aliphatic Alcohols and Related Acid Metabolites in Zebrafish Embryos - Correlations with Rat Developmental Toxicity and with Effects in Advanced Life Stages in Fish. Toxicol. Appl. Pharmacol. 407, 115249-115311. doi:10.1016/j.taap.2020.115249

Waara, P., Hannu, J., Norrby, T., and Byheden, Å. (2001). Additive Influence on Wear and Friction Performance of Environmentally Adapted Lubricants. Tribology Int. 34 (8), 547-556. doi:10.1016/S0301-679X(01)00045-7

Wang, K., Wang, F., Li, J., Huang, Z., Lou, Z., Han, Q., et al. (2019). Synthesis of Trimethylolpropane Fatty Acid Triester as a High Performance Electrical Insulating Oil. Ind. Crops Prod. 142, 111834. doi:10.1016/j.indcrop.2019.111834

Wang, K., Wang, F., Shen, Z., Lou, Z., Han, Q., Li, J., et al. (2020). Breakdown and Streamer Behavior in Homogeneous Synthetic Trimethylolpropane Triesters Insulation Oil. IEEE Trans. Dielect. Electr. Insul. 27 (5), 1501-1507. doi:10. 1109/TDEI.2020.008546

Wang, X., Li, C., Zhang, Y., Ding, W., Yang, M., Gao, T., et al. (2020). Vegetable Oil-Based Nanofluid Minimum Quantity Lubrication Turning: Academic Review and Perspectives. J. Manufacturing Process. 59, 76-97. doi:10.1016/j. jmapro.2020.09.044

Wickramasinghe, K. C., Sasahara, H., Rahim, E. A., and Perera, G. I. P. 2020. Green Metalworking Fluids for Sustainable Machining Applications: A Review. J. Clean. Prod. 257: 120552. doi:10.1016/j.jclepro.2020.120552
Wolf, L. R. (1992). High Performance Food-Grade Lubricating Oil. US Patent US005102567A. filed June 25, 1990, and issued April 7, 1992., issued 1992.

Yunus, R., Fakhru'l-Razi, A., OoiOoi, T. L. S. E. I., Iyuke, S. E., Perez, J. M., TianOoi, Lye., et al. (2004). Lubrication Properties of Trimethylolpropane Esters Based on Palm Oil and Palm Kernel Oils. Eur. J. Lipid Sci. Technol. 106 (1), 52-60. doi:10.1002/ejlt.200300862

Yunus, R., Fakhru'l-Razi, A., OoiOoi, T. L., Omar, R., and Idris, A. (2005). Synthesis of Palm Oil Based Trimethylolpropane Esters with Improved Pour Points. Ind. Eng. Chem. Res. 44 (22), 8178-8183. doi:10.1021/ie050530+

Yunus, R., Hussein, S. R., and Nurin Wahidah, M. Z. (2020). Wear and Friction Behavior of Semi Synthetic Engine Oil Blended with Palm Oil/Tmp Ester and Nano Glass Powder Additive. Jurnal Tribologi 26, 16-36.

Zhan, W., Song, Y., Ren, T., and Liu, W. (2004). The Tribological Behaviour of Some Triazine-Dithiocarbamate Derivatives as Additives in Vegetable Oil. Wear 256 (3-4), 268-274. doi:10.1016/S0043-1648(03)00372-7

Zhu, W., Liang, F., Hou, H., Chen, Y., Liu, X., and Zhu, X. (2020). Enzymatic Synthesis of a Polyol Ester from Levulinic Acid and Trimethylolpropane and its Tribological Behavior as Potential Biolubricant Basestock. Polymers 12 (10), 2256-2264. doi:10.3390/polym12102256

Zulkifli, N. W. M., Azman, S. S. N., Kalam, M. A., Masjuki, H. H., Yunus, R., and Gulzar, M. (2016). Lubricity of Bio-Based Lubricant Derived from Different Chemically Modified Fatty Acid Methyl Ester. Tribology Int. 93, 555-562. doi:10.1016/j.triboint.2015.03.024

Zulkifli, N. W. M., Kalam, M. A., Masjuki, H. H., Shahabuddin, M., and Yunus, R. (2013). Wear Prevention Characteristics of a Palm Oil-Based TMP (Trimethylolpropane) Ester as an Engine Lubricant. Energy 54, 167-173. doi:10.1016/j.energy.2013.01.038

Conflict of Interest: The authors declare that the research was conducted in the absence of any commercial or financial relationships that could be construed as a potential conflict of interest.

The handling editor declared a past co-authorship with one of the authors (RY).

Publisher's Note: All claims expressed in this article are solely those of the authors and do not necessarily represent those of their affiliated organizations, or those of the publisher, the editors, and the reviewers. Any product that may be evaluated in this article, or claim that may be made by its manufacturer, is not guaranteed or endorsed by the publisher.

Copyright (c) 2022 Raof, Hamid, Mohamad Aziz and Yunus. This is an open-access article distributed under the terms of the Creative Commons Attribution License (CC $B Y)$. The use, distribution or reproduction in other forums is permitted, provided the original author(s) and the copyright owner(s) are credited and that the original publication in this journal is cited, in accordance with accepted academic practice. No use, distribution or reproduction is permitted which does not comply with these terms. 